\title{
Camellia sinensis and epicatechin abate doxorubicin-induced hepatotoxicity in male Wistar rats via their modulatory effects on oxidative stress, inflammation, and apoptosis
}

\author{
Osama M. Ahmed ${ }^{1 *}$, Manal M. Abdul-Hamid², Ahlam M. El-Bakry³, Hanaa M. Mohamed ${ }^{2}$, Fatma El-Zahraa S. Abdel Rahman ${ }^{4}$ \\ ${ }^{1}$ Physiology Division, Department of Zoology, Faculty of Science, Beni-Suef University, Beni-Suef, Egypt. \\ ${ }^{2}$ Cell Biology, Histology and Genetics Division, Department of Zoology, Faculty of Science, Beni-Suef University, Beni-Suef, Egypt. \\ ${ }^{3}$ Comparative Anatomy and Embryology Division, Department of Zoology, Faculty of Science, Beni-Suef University, Beni-Suef, Egypt. \\ ${ }^{4}$ Department of Basic Sciences, Faculty of Oral and Dental Medicine, Nahda University, Beni-Suef, Egypt.
}

\section{ARTICLE INFO \\ Received on: 09/11/2018 \\ Accepted on: 05/03/2019 \\ Available online: 18/04/2019}

\section{Key words:}

Camellia sinensis, epicatechin, doxorubicin, hepatotoxicity, rats.

\begin{abstract}
This study aimed to assess the preventive effects of Camellia sinensis (green tea) leaf aqueous extract and epicatechin and to scrutinize their possible mechanisms of action in doxorubicin (Dox)-induced liver injury. Phytochemical screening of $C$. sinensis aqueous extract was performed by liquid chromatography electrospray ionization tandem mass spectrometry that revealed the presence of epicatechin and other polyphenols. Male Wistar rats were intraperitoneally injected with Dox (4 mg/kg/week) and were orally treated with C. sinensis aqueous extract $(200 \mathrm{mg} / \mathrm{kg})$ or epicatechin $(25 \mathrm{mg} / \mathrm{kg})$ every other day for 6 weeks. The treatments of Dox-injected rats with the extract and epicatechin resulted in a marked amelioration of the deteriorated effects on albumin, alpha-fetoprotein, and total bilirubin levels as well as alanine transaminase, aspartate transaminase, alkaline phosphatase, and gamma glutamyl tansferase activities. The treatments also alleviated the altered serum tumor necrosis factor-alpha and interleukin-4, liver lipid peroxidation, and glutathione levels as well as liver superoxide dismutase, glutathione peroxidase, and glutathione-S-transferase activities. In association, the expression of liver nuclear factor-kappa B cells, cyclooxygenase-2, p53, and caspase-3 was remarkably decreased, the expression of Bcl-2 was significantly increased, and the liver histological architecture was remarkably amended by treatments. Camellia sinensis aqueous extract and epicatechin may have effective chemopreventive potentials against Dox-induced hepatotoxicity via reinforcement of antioxidant defense system and attenuation of the inflammatory and apoptotic effects.
\end{abstract}

\section{INTRODUCTION}

The liver, as vital organ, performs an array of complex functions coordinating metabolic, immunologic, and detoxification processes (Sendensky and Dufour, 2011). Despite the liver's substantiality and unique self-regeneration capability, viral infection, parasite infection, autoimmune diseases, fatty liver disorder, drug-induced hepatotoxicity, and alcohol abuse all contribute to the increasing prevalence of liver failure (Bai et al., 2016).

"Corresponding Author

Osama M. Ahmed, Physiology Division, Department of Zoology, Faculty of Science, Beni-Suef University, Beni-Suef, Egypt.

Email:osamamoha@yahoo.com; osama.ahmed@science.bsu.edu.eg
Doxorubicin (Dox) is an anthracycline antibiotic that has been commonly used to treat multiple types of cancers (Xi et al., 2012). Although Dox is an effective anti-cancer agent, its use is significantly limited owing to its side effects and toxicity (Ahmed et al., 2019). This Dox toxicity often affects many organs such as liver, heart, brain, kidneys, and testes, thereby limiting its clinical application (Tacar et al., 2013; Trivedi et al., 2011). Mitochondria were suggested to be one of the main targets of Dox which produces its action through mitochondria-mediated apoptosis leading to modifications in mitochondrial membranes; this, in turn, results in alterations in oxidative phosphorylation and respiratory chain complexes in the mitochondria (Trivedi et al., 2011). Moreover, Dox significantly deteriorates energy-signaling and -transducing systems like 
adenosine monophosphate-activated protein kinase and creatine kinase (Kuznetsova et al., 2011).

Dox causes perturbance in the balance between the reactive oxygen species (ROS) generation on the one hand and the antioxidant defense system on the other hand leading to tissue injuries (Karaman et al., 2006; Saad et al., 2011). Several studies were conducted for the screening of the antioxidants derived from the medicinal plants and natural sources aiming to minimize oxidative damage by Dox (Kaiserova et al., 2007). In this regard, many of these antioxidants were elucidated to amend the Dox-induced cellular degeneration without affecting its anti-cancer efficacies (Xin et al., 2011).

Green tea, Camellia sinensis (C. sinensis) is one of the most commonly consumed beverages after water (Subhashini et al., 2010). Its phytochemical screening by previous publications indicated the presence of phenolics, flavonoids, alkaloids, tannins, steroids, terpenoids, glycosides, and saponins (Geoffrey et al., 2014; Rahman, 2016; Subhashini et al., 2010). Polyphenols, including flavonoids, constitute up to $30 \%$ of the green tea leaves, but only $10 \%$ of black tea by dry weight (Subhashini et al., 2010). Three basic flavonoids in tea leaves include catechins, theaflavins, and thearubigins (Cui et al., 2008; Yanishlieva-Maslarowa and Heinonen, 2001).

Catechins have many biological activities and they are extensively used as potent protective and preventive agents (Rahmani et al., 2015). They possess anticancer, anti-obesity, hypocholesterolemic, and hypoglycemic properties (Kanwar et al., 2012). Green tea and its constituent catechins have widely been investigated for their therapeutic, protective, and preventive effects against cancer and other diseases (Cui et al., 2008; Lecumberri et al., 2013). Their benefits such as weight loss via stimulating the rate of metabolism, total cholesterol level reduction, high-density lipoprotein increase, and plague prevention have been previously demonstrated (Alappat et al., 2015; Khan and Mukhtar, 2010). In addition, the green tea extracts and their catechin components have been elucidated to have potent antioxidant activities that play an important role in the prevention and therapy of multiple diseases (Rahman, 2016).

Therefore, this current study was conducted to assess the preventive efficacies of $C$. sinensis aqueous extract and its constituent, epicatechin, on Dox-induced liver injury and to suggest their probable mechanisms of action.

\section{MATERIALS AND METHODS}

\section{Experimental animals}

Male Wistar rats weighing from 140 to $180 \mathrm{~g}$ and aging 8-10 weeks were purchased from Research Institute of Ophthalmology, 2 El Ahram Street, Giza, Egypt. To exclude any interchange infection, the rats were overseen for about 2 weeks before the initiation of the experiment. The animals, chosen for study, were housed in polypropylene cages with good aerated stainless steel covers at normal atmospheric temperature $\left(25^{\circ} \mathrm{C}\right.$ $\pm 5^{\circ} \mathrm{C}$ ) as well as 12-hour daily normal light periods in the Animal House in Faculty of Science, Beni-Suef University, Beni-Suef Governorate, Egypt. Moreover, the rats were daily supplied with excess water and standard pellet diet ad libitum. By the way, all animal experiments and procedures followed the recommendations of the Canadian Council on Animal Care (CCAC) (2010) and are in concordance with the guidelines and instructions for animal use and care of Experimental Animal Ethics Committee of Faculty of Science, Beni-Suef University, Egypt (Ethical Consent Number: BSU/FS/2014/8).

\section{Chemicals and drugs}

Dox hydrochloride (adricin 10-mg vials), manufactured by Pharmacia Italia Nerviano Italy, was obtained from El Gomhuria Pharmacy, Cairo, Egypt. Green tea was purchased from Harraz Medicinal Plant Company, 1 Ahmed Maher Street, Bab Al Khalq, Cairo, Egypt (www.harrazegypt.com). Epicatechin of the chemical structure indicated in Figure 1 (Rozza et al., 2012) was purchased from Sigma Chemical Company, St. Louis, MQ. Saline ( $0.9 \%$ sodium chloride) was obtained from ADWIC Company and produced by El-Nasr Pharmaceutical Chemical Company, Cairo, Egypt. Carboxymethyl cellulose (CMC) was obtained from the Egyptian Center for Chemicals and Laboratory Supplies, Nasr City, Cairo, Egypt. All other used chemicals are ultrapure and are of analytical grade.

Analysis of green tea using the liquid chromatography electrospray ionization tandem mass spectrometry (LC/ESIMS/MS)

Liquid chromatography (LC) coupled with mass spectrometry (MS) and a source of electrospray ionization tandem mass spectrum (ESI-MS) were used for chemical analysis of green tea extract.

The separation of the green tea sample was performed according to Yoshida and Majors (2006) method with some modifications on ZORBAX-C18 $(4.6 \times 100 \mathrm{~mm}$ id, $3.5 \mu \mathrm{m})$ analytical column using LC/deuterium-arc-discharge (DAD)/ MS system Agilent 1100 quaternary pump, coupled with a DAD (Agilent 6120 quadruple spectrometer, CA, USA) wavelength setting of $280 \mathrm{~nm}$. The instrument conditions are as follows: pressure was 45.5 bar at starting point and 55.9 bar at stopping point; the flow rate of the mobile phase was $0.4 \mathrm{ml} /$ minute with a column compartment temperature of $40^{\circ} \mathrm{C}$ and an injection volume of $10 \mu \mathrm{l}$. The mobile phase was composed of $0.2 \%$ formic acid in water (Solvent A) and $0.1 \%$ formic acid in acetonitrile (Solvent B) in a gradient elution mode. The gradient elution was conditioned as follows: initial concentration of $10 \%$

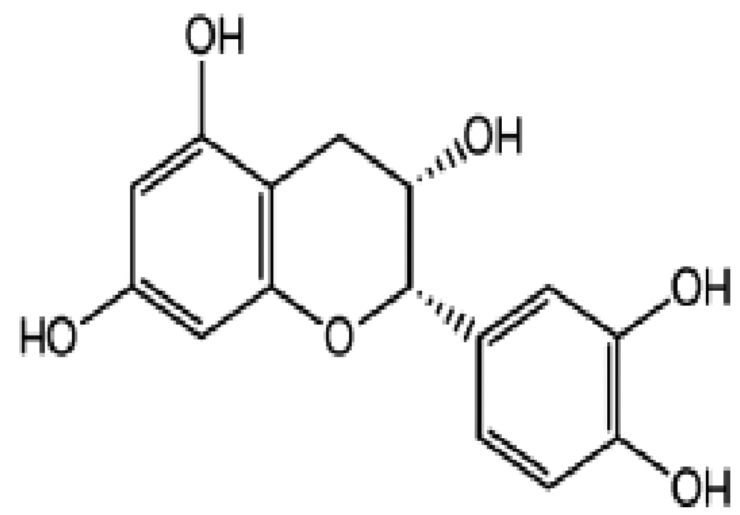

Figure 1. Chemical structure of epicatechin (Rozza et al., 2012). 
$\mathrm{B}$ with programing to $15 \% \mathrm{~B}$ for 15 minutes, and then to $27 \% \mathrm{~B}$ for another 15 minutes. The column was then equilibrated under the initial condition for 10 minutes.

The mass selective detector instrument and ESI conditions were as follows: vaporized temperature or gas temperature, $350^{\circ} \mathrm{C}$; nebulizer gas, nitrogen, at a pressure 50 psi; and drying gas, also nitrogen, at a flow rate $12 \mathrm{l} /$ minute and capillary voltage, $-3,500 \mathrm{~V}$ of negative mode and 3,500 $\mathrm{V}$ of positive mode, and scan range $100-1,000 \mathrm{~m} / \mathrm{z}$. ESI of the catechins in -ve mode produces the $[\mathrm{M}-\mathrm{H}]^{-}$molecular adduct ion while ESI of the caffeine in + ve mode produces the $[\mathrm{M}+\mathrm{H}]^{+}$ molecular adduct ion.

\section{Dose preparation of Dox}

Dox at dose $4 \mathrm{mg} / \mathrm{kg}$ body weight (b.w.)/week was prepared for intraperitoneal (i.p.) injection in 1 weekly dose for 6 weeks according to Trivedi et al. (2011).

\section{Dose preparation of green tea aqueous extract and epicatechin}

Green tea, $C$. sinensis, belonging to the Theaceae family, was authenticated by Dr. Walaa A. Hassan, Assistant professor of Taxonomy and Flora, Botany Department, Faculty of Science, Beni-Suef University, Salah Salem Street, Beni-Suef, Egypt. The herb was deposited in the Herbarium of Botany Department, Faculty of Science, Beni-Suef University, Egypt. The dried green tea leaves were grinded into powder by an electric grinder. The aqueous extract was prepared from the tea leaves powder based on the methods of Ahmed (2010) and Swanston-Flatt et al. (1990). The powder of green tea leaves was mixed with the already boiled distilled sterile water $(2 \mathrm{~g} / 50 \mathrm{ml} ; 4 \% \mathrm{w} / \mathrm{v})$ and infused for 15 minutes. The aqueous extract was then filtered and the obtained filtrate was freshly used for oral administration to Dox-administered rats at a dose of $200 \mathrm{mg} / \mathrm{kg}$ b.w. according to Al-Hilfy (2012).

Epicatechin was prepared by dissolving the required dose in 1\% CMC (25 mg/5 ml 1\% CMC/kg b.w.).

\section{Animal grouping}

Forty Wistar rats were randomly divided into 4 groups of 10 animals each as follows:

\section{Group 1 (Normal control group)}

In this group, the rats received the equivalent volume of saline which was intraperitoneally (i.p.) injected/week for 6 weeks. The rats of this group were also given the equivalent volume of the vehicle ( $1 \% \mathrm{CMC}$ solution) by oral gavage every other day for 6 weeks.

\section{Group 2 (Dox-administered group)}

Dox dissolved in saline was injected i.p. as a total cumulative dose of $24 \mathrm{mg} / \mathrm{kg}$ b.w. divided into six equal doses, each of $4 \mathrm{mg} / \mathrm{kg}$ b.w./week for 6 weeks Trivedi et al. (2011). The rats of this group were also given the same volume of the vehicle ( $1 \% \mathrm{CMC}$ solution) by oral gavage every other day for 6 weeks.

Group 3 (Dox-administerated rats treated with green tea aqueous extract)

This group was given Dox as group 2 plus green tea aqueous extract by oral gavage at a dose of $200 \mathrm{mg} / \mathrm{kg}$ b.w. every other day for 6 weeks (Al-Hilfy, 2012). The rats of this group were given the same volume of the vehicle ( $1 \% \mathrm{CMC}$ solution) as in groups 1,2 , and 4 by oral gavage every other day for 6 weeks.

\section{Group 4 (Dox-administerated rats treated with epicatechin)}

In this group, the rats were administered Dox as group 2 plus epicatechien (dissolved in 1\% CMC solution) by oral gavage at a dose of $25 \mathrm{mg} / 5 \mathrm{ml} / \mathrm{kg}$ b.w. every other day for 6 weeks (Vasconcelos et al., 2012).

\section{Preparation of blood and tissue homogenates}

At the end of the 6 weeks of treatment periods, animals were sacrificed under diethyl ether anesthesia. Then, blood from each rat was collected from jugular veins into gel and clot activator tubes. The sera were quickly aspirated by Pasteur pipette and divided into three nearly equal portions for each individual rat, and kept in a deep freezer at $-20^{\circ} \mathrm{C}$ for subsequent analysis. After decapitation by cervical dislocation and dissection, liver of each rat was quickly removed, weighed, and homogenized in a sterile saline $(0.9 \% \mathrm{NaCl}$ solution; $10 \% \mathrm{w} / \mathrm{v})$ using Teflon homogenizer (Glas-Col; Terre Haute, IN). Then, the homogenates were centrifuged at 3,000 rpm. for 15 minutes and the supernatants were separated by Pasteur pipette and kept at $-20^{\circ} \mathrm{C}$ pending determination of antioxidant defense system and oxidative stress biomarkers

\section{Assay of liver function parameters in serum}

Serum alanine transaminase (ALT), aspartate transaminase (AST), gamma glutamyl tansferase (GGT), and alkaline phosphatase (ALP) activities were assayed according to the methods of Gendler (1984), Murray (1984a; 1984b), and Tietz et al. (1983), respectively, using reagent kits purchased from Spinreact, 7 E-17176 Sant Esteve De Bas (Gi), Spain. Serum total bilirubin level was detected based on the procedure of Jendrassik and Grof (1938) using reagent kits purchased from Spectrum Diagnostics, Cairo, Egypt. Serum albumin level was estimated according to Doumas et al. (1971) using kits obtained from Diamond Diagnostics (Cairo, Egypt).

\section{Assay of lipid peroxidation and antioxidant parameters}

Glutathione (GSH) content in liver homogenates was detected based on the chemical method of Beutler et al. (1963). Lipid peroxidation (LPO) in homogenates was estimated based on the chemical method of Preuss et al. (1978). Glutathione peroxidase (GPx; EC 1.11.1.7), superoxide dismutase (SOD; EC 1.15.1.1), and glutathione-S-transferase (GST; EC 2.5.1.18) activities in liver homogenates were assayed based on the methods of Kar and Mishra (1976), Mannervik and Guthenberg (1981), and Marklund and Marklin (1974), respectively.

\section{Detection of liver mRNA expression of various markers of apoptosis and inflammation}

RNA purification from liver tissue was carried out by using GeneJET RNA Purification kits purchased from Thermo Fisher Scientific Inc., Rochester, New York, according to the method of Chomzynski and Sacchi (1987).

Reverse transcription and PCR amplification were carried out by Thermo Cycler PCR (Techne 32 Thermocycler) 
using single step Verso 1-Step reverse transcriptase-polymerase chain reaction (RT-PCR) ReddyMix kit purchased from Thermo Fisher Scientific Inc. Rochester, New York, in the presence of specific primers (Table 1) of protein 53 (p53) (Asiri, 2010), B-cell lymphoma 2 (Bcl2) (Ashok and Sheeladevi, 2014), nuclear factor-kappa B cells (NF- $\mathrm{KB}$ ) (Ahmed et al., 2016), and protein of housekeeping gene, $\beta$-actin (Ahmed et al., 2017), supplied from Biosearch Technologies, South McDowell Blud, Petaluma. After gel electrophoresis, the gel containing bands was transferred to Gel Documentation Unit and photos were taken. The photos of gene bands were analyzed with GelDocu Advanced Program from Raya for the Scientific Services, Giza, Egypt, and represented as numbers for statistical analysis. The mRNA expression of p53, $\mathrm{Bcl} 2$, and $\mathrm{NF}-\kappa \mathrm{B}$ was related to $\beta$-actin.

\section{ELISA assay}

Serum tumor necrosis factor-alpha (TNF- $\alpha)$, interleukin-4 (IL-4), and alpha-fetoprotein (AFP) levels were detected by using specific enzyme-linked immunosorbent assay (ELISA) kits obtained from R\&D Systems, Inc., Minneapolis, $\mathrm{MN}$, according to manufacturer's instructions.

\section{Histological investigation}

After sacrifice and dissection at the end of the experiment, pieces of liver from each rat were immediately excised, fixed in $10 \%$ phosphate buffered formalin $(\mathrm{pH} \mathrm{7.2)}$, and transported to Pathology Department, Faculty of Veterinary Medicine, Beni-Suef University, Egypt, for further processing, sectioning, mounting of sections on slides, and staining with hematoxylin and eosin (H\&E) (Bancroft et al., 1996). The stained sections were examined for the detection of lesions.

\section{Immunohistochemical investigation}

Liver samples, fixed in 10\% neutral phosphate buffered formalin, were dehydrated and embedded in paraffin, cut into $5-\mu \mathrm{m}$ sections, and mounted on positive slides. The COX2 in liver tissue sections was detected by using anti-COX-2 and anti-caspase-3 specific IgG (H-62, sc-7951, Santa Cruz Biotechnology, Dallas, TX). The sections prepared from the liver were mounted on positive slides for detection of COX-2 (Therland et al., 2004). Immunolocalization technique for caspase-3 was prepared on 5 - $\mu \mathrm{m}$ thickness liver sections according to Hussein and Ahmed (2010) and Pedrycz and Czerny (2008). The positive

Table 1. The sequences of forward and reverse primers of selected genes.

\begin{tabular}{|c|c|c|}
\hline Detected gene & Primer sequence & Reference \\
\hline \multirow{2}{*}{ P53 } & F: 5 d CAGCGTGATGATGGTAAGGA3' & \multirow[t]{2}{*}{ Asiri (2010) } \\
\hline & R: 5 d GCGTTGCTCTGATGGTGA3' & \\
\hline \multirow{2}{*}{ Bcl-2 } & F: 5 d GGGATGCCTTTGTGGAACTA3' & \multirow{2}{*}{$\begin{array}{l}\text { Ashok and Sheeladevi } \\
\text { (2014) }\end{array}$} \\
\hline & R: 5 d CTCACTTGTGGCCCAGGTAT3' & \\
\hline \multirow{2}{*}{$\mathrm{NF}-\kappa \mathrm{B}$} & F: 5'd TACCATGCTGTTTTGGTTAC3' & \multirow[t]{2}{*}{ Ahmed et al. (2016) } \\
\hline & R: 5'dTCAAGCTACCAATGACTTTC3' & \\
\hline \multirow{2}{*}{$\beta$-actin } & F:5TCACCCTGAAGTACCCCATGGAG3' & \multirow[t]{2}{*}{ Ahmed et al. (2017) } \\
\hline & R: 5 d TTGGCCTTGGGGTTCAGGGGG3' & \\
\hline
\end{tabular}

reaction in cytoplasm of hepatocytes appeared brownish in color (Giorno, 1984).

\section{Statistical analysis}

Data were analyzed by SPSS v. 20. Results were expressed as mean \pm standard error mean $(\mathrm{SEM})$ and all statistical comparisons were made by Duncan's test post-hoc analysis and least significance difference. $p$ values at $p>0.05$ were considered non-significant, while those at $p<0.05$ were considered significant.

\section{RESULTS}

\section{Phytochemical screening}

The chemical analysis of green tea extract by LC/ESIMS/MS indicated the presence gallic acid, (-)-gallocatechin, (-)-epigallocatechin, caffeine, (-)-epicatechin, (-)-epigallocatechin gallate, (-)-gallocatechin gallate, (-)-epicatechin gallate, and (-)-catechin gallate (Fig. 2).

\section{Effect on liver function parameters in serum}

Serum AFP and total bilirubin levels exhibited a significant increase $(p<0.05)$ in Dox-administered animals recording percentage increases of $418.18 \%$ and $137.50 \%$, respectively, in comparison with the normal control group. On the contrary, serum albumin level was significantly $(p<0.05)$ decreased in Dox-administrated rats recording percentage change of $-17.44 \%$. The treatment of Dox-administered rats with green tea aqueous extract produced a significant decrease $(p<0.05)$ of the elevated serum AFP and total bilirubin levels; the recorded percentage decreases were $-66.67 \%$ and $-17.54 \%$, respectively, in comparison with Dox-administered control. The decreased serum albumin level was non-significantly $(p>0.05)$ elevated as a result of treatment of Dox-administrated rats with green tea aqueous extract. The treatment of Dox-administered rats with epicatechin caused a significant decrease of the serum AFP $(p<0.05)$ levels recording percentage decrease $-67.54 \%$ while it produced a non-significant decrease of serum total bilirubin level recording percentage decrease $-5.26 \%$. In contrast, the albumin level exhibited a non-significant increase $(p>0.05)$ in Dox-administered rats recording percentage increase of $1.10 \%$. Green tea aqueous extract was more potent in improving the altered serum albumin and total bilirubin levels (Table 2).

Serum ALT, AST, ALP, and GGT activities showed a significant elevation $(p<0.05)$ in Dox-administered rats recording percentage increases of $65.23 \%, 31.35 \%, 56.60 \%$, and $218.75 \%$, respectively, when compared with the normal control group. The treatment of Dox-administered rats with green tea resulted in a significant decrease of the elevated serum ALT, AST, ALP, and GGT activities $(p<0.05)$; the recorded percentage changes were $-46.02 \%,-35.78 \%,-52.45 \%$, and $-30.72 \%$, respectively, in comparison with Dox-administered rats. The treatment of Doxadministered rats with epicatechin produced a significant decrease $(p<0.05)$ in serum ALT, AST, and ALP activities recording percentage changes of $-42.57 \%,-24.51 \%,-57.43 \%$, and $-54.90 \%$, respectively, in comparison with Dox-administered rats. While green tea aqueous extract was more potent in improving the elevated serum ALT and AST activities, epicatechin was more effective in alleviating the elevated serum ALP activity. The serum 
GGT activity, on the other hand, was significantly $(p<0.05)$ decreased as a result of treatment of Dox-administered rats with green tea aqueous extract, while it was significantly $(p<0.05)$ increased due to epicatechin treatment (Table 3).

\section{Effect on serum TNF- $\alpha$ and IL-4 levels}

With regard to ELISA results, the Dox-administered rats showed a marked $(p<0.05)$ rise in serum TNF- $\alpha$ level and decrease in serum IL-4 level recording percentage changes of $288.81 \%$ and $-64.10 \%$, respectively, as compared with normal control group. As a result of treatment of Dox-administered rats with green tea aqueous extract, a significant $(p<0.05)$ decrease in serum TNF- $\alpha$ level and increase of IL-4 level were produced; the recorded percentage changes were $-63.29 \%$ and $110.32 \%$, respectively, as compared with Dox-administered rats. The treatment of Dox-administered rats with epicatechin caused a significant decrease in serum TNF- $\alpha$ level and increase of IL-4 serum level recording percentage changes of $-51.06 \%$ and $106.80 \%$, respectively, when compared to Dox-administered group. Thus, green tea aqueous extract seems to be more potent in improving the proinflammatory cytokine, TNF- $\alpha$, and antiinflammatory cytokine, IL-4 (Table 4).

\section{Effect on liver oxidative stress and anti-oxidant defense system}

Liver SOD activity in Dox-administered rats exhibited a significant decrease $(p<0.05)$ recording percentage decrease of $-20.92 \%$ when compared with the normal group. In contrast, LPO in the liver of Dox-administered rats was significantly increased $(p<0.05)$ recording percentage increase of $247.12 \%$ when compared with the normal group. The treatment of Dox-administered rats with green tea aqueous extract and epicatechin, respectively, resulted in a non-significant $(p>0.05)$ and a significant $(p<0.05)$ increases of liver SOD activity; the recorded percentage increases were $14.03 \%$ and $13.50 \%$, respectively, as compared with Dox-administered rats. In contrast, hepatic LPO was significantly decreased $(p<0.05)$ in Dox-administered rats treated with green tea aqueous extract and epicatechin recording percentage decreases of $-34.83 \%$ and $-60.52 \%$, respectively, when compared with Dox-administered rats, while the effect of green tea aqueous extract and epicatechin

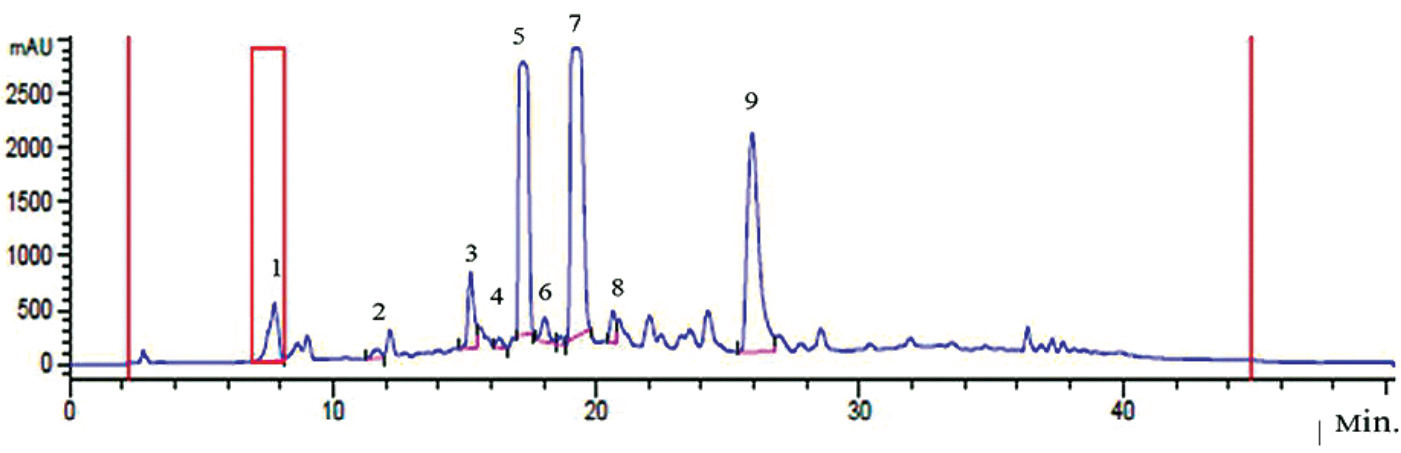

Figure 2. LC/ESI-MS of green tea extract. Peaks identification: 1: gallic acid; 2: (-)-gallocatechin; 3: (-)-gallocatechin; 4: (-)-epigallocatechin; 5: caffeine; 6: (-)-epicatechin; 7: (-)-epigallocatechin gallate; 8: (-)-gallocatechin gallate; and 9: (-)-epicatechin gallate and (-)-catechin gallate. These results are shared with our other publication (Ahmed et al., 2019).

Table 2. Effect of green tea aqueous extract and epicatechin on serum albumin, AFP, and total bilirubin levels in Dox-administered rats.

\begin{tabular}{lccc}
\hline Experimental conditions & $\begin{array}{c}\text { Albumin } \\
(\mathbf{g} / \mathbf{d l})\end{array}$ & $\begin{array}{c}\text { AFP } \\
(\mathbf{n g} / \mathbf{m l})\end{array}$ & Total bilirubin $(\boldsymbol{\mu m o l} / \mathbf{l})$ \\
\hline Control & $3.60 \pm 0.07$ & $0.22 \pm 0.03$ & $0.24 \pm 0.02$ \\
Dox & $2.97 \pm 0.09^{\mathrm{a}}$ & $1.14 \pm 0.13^{\mathrm{a}}$ & $0.57 \pm 0.03^{\mathrm{a}}$ \\
$\%$ change & $(-17.50 \%)$ & $(+418.18 \%)$ & $(+137.50 \%)$ \\
Dox $+\mathrm{GT}$ & $3.13 \pm 0.10$ & $0.38 \pm 0.15^{\mathrm{b}}$ & $0.47 \pm 0.02^{\mathrm{b}}$ \\
$\%$ change & $(+5.39 \%)$ & $(-66.67 \%)$ & $(-17.54 \%)$ \\
Dox $^{\mathrm{B}}+\mathrm{Epi}^{\mathrm{b}}$ & $3.00 \pm 0.06$ & $0.37 \pm 0.08^{\mathrm{b}}$ & $0.54 \pm 0.02$ \\
$\%$ change & $(+1.10 \%)$ & $(-67.54 \%)$ & $(-5.26 \%)$ \\
\hline
\end{tabular}

Data are represented as a mean \pm SEM. The number of animals in each group is six.

${ }^{\text {ab }}$ Significant differences in comparison with the corresponding control and Dox-administered groups, respectively, at $p<0.05$.

A,BPercentage of changes in relation to the normal control and Dox-administered groups, respectively.

GT: green tea aqueous extract; Epi: epicatechin. 
Table 3. Effect of green tea aqueous extract and epicatechin on serum ALT, AST, ALP, and GGT activities in Dox-administered rats.

\begin{tabular}{|c|c|c|c|c|}
\hline Experimental conditions & $\operatorname{ALT}(\mathbf{U} / \mathbf{l})$ & $\operatorname{AST}(\mathbf{U} / \mathbf{l})$ & $\operatorname{ALP}(\mathbf{U} / \mathbf{l})$ & GGT (U/I) \\
\hline Control & $34.60 \pm 1.21$ & $154.80 \pm 5.70$ & $193.80 \pm 5.55$ & $0.48 \pm 0.09$ \\
\hline Dox & $57.17 \pm 2.10^{\mathrm{a}}$ & $203.33 \pm 6.35^{\mathrm{a}}$ & $303.51 \pm 2.88^{\mathrm{a}}$ & $1.53 \pm 0.09^{\mathrm{a}}$ \\
\hline$\%$ change $^{\mathrm{A}}$ & $(+65.23 \%)$ & $(+31.35 \%)$ & $(+56.60 \%)$ & $(+218.75 \%)$ \\
\hline Dox + GT & $30.86 \pm 1.45^{b}$ & $130.57 \pm 2.50^{b}$ & $144.30 \pm 8.32^{b}$ & $1.06 \pm 0.06^{\mathrm{b}}$ \\
\hline$\%$ change $^{\mathrm{B}}$ & $(-46.02 \%)$ & $(-35.78 \%)$ & $(-52.45 \%)$ & $(-30.72 \%)$ \\
\hline Dox + Epi & $32.83 \pm 1.45^{\mathrm{b}}$ & $153.50 \pm 4.87^{\mathrm{b}}$ & $129.20 \pm 4.49^{b}$ & $2.37 \pm 0.08^{b}$ \\
\hline$\%$ change $^{\mathrm{B}}$ & $(-42.57 \%)$ & $(-24.51 \%)$ & $(-57.43 \%)$ & $(+54.90 \%)$ \\
\hline
\end{tabular}

Data represented as a mean \pm SEM. The number of animals in each group is six.

a,bignificant difference in comparison with the corresponding control and Dox-administered groups, respectively, at $p<0.05$.

$\mathrm{A}, \mathrm{B}$ Percentage of changes in relation to the normal control and Dox-administered groups, respectively.

GT: green tea aqueous extract; Epi: epicatechin.

Table 4. Effect of green tea aqueous extract and epicatechin on serum TNF- $\alpha$ and IL-4 levels in Dox-administered rats.

\begin{tabular}{|c|c|c|}
\hline Experimental conditions & TNF- $\alpha(\mathrm{pg} / \mathrm{ml})$ & IL-4 (pg/ml) \\
\hline Control & $28.25 \pm 2.22$ & $134.71 \pm 5.33$ \\
\hline Dox & $109.84 \pm 10.58^{\mathrm{a}}$ & $48.36 \pm 2.90^{\mathrm{a}}$ \\
\hline$\%$ change $^{\mathrm{A}}$ & $(+288.81 \%)$ & $(-64.10 \%)$ \\
\hline Dox + GT & $40.32 \pm 2.54^{\mathrm{b}}$ & $101.71 \pm 5.83^{\mathrm{b}}$ \\
\hline$\%$ change $^{\mathrm{B}}$ & $(-63.29 \%)$ & $(+110.32 \%)$ \\
\hline Dox + Epi & $53.77 \pm 4.40^{\mathrm{b}}$ & $100.01 \pm 3.92^{\mathrm{b}}$ \\
\hline$\%$ change $^{\mathrm{B}}$ & $(-51.06 \%)$ & $(+106.80 \%)$ \\
\hline
\end{tabular}

Data represented as a mean \pm SEM. The number of animals in each group is six.

${ }^{\mathrm{a}, \mathrm{b}}$ Significant differences in comparison with the corresponding normal control and Dox-administered groups, respectively, at $p<0.05$.

$\mathrm{A}, \mathrm{B}$ Percentage of changes in relation to the normal control and Dox-administered groups, respectively.

GT: green tea aqueous extract; Epi: epicatechin.

on liver LPO activity was more or less similar, the effect of epicatechin was more potent on liver LPO (Table 5).

Dox-administration caused a marked depletion $(p<0.05)$ of hepatic GSH content as well as GPx and GST stores when compared with the normal group; the recorded percentage changes were $-33.78 \%,-26.99 \%$, and $-33.45 \%$, respectively. The treatment of Dox-administered rats with green tea aqueous extract significantly $(p<0.05)$ prevented this depletion in GSH content and GPx activity recording percentage changes of $21.25 \%$ and $39.40 \%$, respectively. In contrast, GST activity was non-significantly affected as a result of green tea aqueous extract treatment recording a percentage change of $3.28 \%$. The treatment of DOX-administered rats with epicatechin produced a significant increase $(p<0.05)$ of the serum GSH content as well as GPx stores; the recorded percentage changes were $20.29 \%$ and $34.22 \%$, respectively. In contrast, GST activity was non-significantly affected due to epicatechin treatment recording a percentage change of $-8.60 \%$, while the effects of green tea aqueous extract and epicatechin were more or less similar on liver GSH content, the effect of green tea aqueous extract was potent on liver GPx activity (Table 6).

\section{Effect on mRNA expression of liver p53, Bcl2, and NF-кB}

The mRNA expression of $\mathrm{p} 53$ relative to $\beta$-actin exhibited a significant $(p<0.05)$ elevation in Dox-administered rats recording percentage increases of $164.91 \%$ when compared with the normal group. The treatment of Dox-administered rats with green tea aqueous extract and epicatechin produced a significant $(p<0.05)$ decrease of the elevated p53 mRNA expression recording percentage changes of $-48.60 \%$ and $-75.40 \%$, respectively, when compared with Dox-administered control. Thus, the effect of epicatechin was more potent than green tea aqueous extract on decreasing the elevated mRNA expression of $\mathrm{p} 53$ relative to $\beta$-actin (Fig. 3).

The mRNA expression of $\mathrm{Bcl} 2$ relative to $\beta$-actin exhibited a significant decrease $(p<0.05)$ in Dox-administered rats recording percentage changes of $-81.50 \%$ when compared with the normal control group. The treatment of Dox-administered rats with green tea aqueous extract and epicatechin produced a significant $(p<0.05)$ increase of the lowered $\mathrm{Bcl} 2 \mathrm{mRNA}$ expression recording percentage changes of $409.01 \%$ and $378.22 \%$, respectively, when compared with Dox-administered control (Fig. 4).

The mRNA expression of liver $\mathrm{NF}-\kappa \mathrm{B}$ relative to $\beta$-actin exhibited a significant $(p<0.05)$ increase in Dox-administered rats recording percentage increases of $48.51 \%$ as compared with the normal group. The treatment of Dox-administered rats with green tea aqueous extract and epicatechin produced a significant $(p<0.05)$ decrease of the elevated liver NF- $\kappa \mathrm{B}$ mRNA expression recording percentage changes of $-31.20 \%$ and $-49.10 \%$, respectively, as compared with Dox-administered control. The epicatechin was more effective than green tea aqueous extract in 
Table 5. Effect of green tea aqueous extract and epicatechin on liver SOD activity and lipid peroxidation in Dox-administered rats.

\begin{tabular}{lcc}
\hline Experimental conditions & $\begin{array}{c}\text { SOD activity } \\
\text { (U/g tissue) }\end{array}$ & $\begin{array}{c}\text { LPO } \\
\text { (nmol/100 mg tissue/hour) }\end{array}$ \\
\hline Control & $16.49 \pm 1.38$ & $5.41 \pm 0.57$ \\
Dox & $13.04 \pm 0.539^{\mathrm{a}}$ & $20.24 \pm 1.65^{\mathrm{a}}$ \\
$\%$ change & $(-20.92 \%)$ & $(+274.12 \%)$ \\
Dox $+\mathrm{GT}$ & $14.87 \pm 1.722$ & $13.19 \pm 1.44^{\mathrm{b}}$ \\
$\%$ change & $(+14.03 \%)$ & $(-34.83 \%)$ \\
Dox $^{\mathrm{B}}$ Epi $^{\mathrm{A}}$ & $14.80 \pm 0.56^{\mathrm{b}}$ & $7.99 \pm 1.48^{\mathrm{b}}$ \\
\% change & $(+13.50 \%)$ & $(-60.52 \%)$ \\
\hline
\end{tabular}

Data represented as a mean $\pm \mathrm{SEM}$. The number of animals in each group is six.

${ }^{\mathrm{a}, \mathrm{b}}$ Significant difference in comparison with the corresponding normal control and Dox-administered groups, respectively, at $p<0.05$.

A,BPercentage of changes in relation to the normal control and Dox-administered groups, respectively.

GT: green tea aqueous extract; Epi: epicatechin.

Table 6. Effects of green tea aqueous extract and epicatechin on liver GSH content and GPx and GST activities in Dox-administered rats.

\begin{tabular}{|c|c|c|c|}
\hline Experimental conditions & $\begin{array}{c}\text { GSH } \\
\text { (nmol/100 } \mathrm{mg} \\
\text { tissue) }\end{array}$ & $\begin{array}{c}\text { GPx } \\
\text { (mU/100 mg } \\
\text { tissue) }\end{array}$ & $\begin{array}{c}\text { GST } \\
\text { (U/100 mg tissue) }\end{array}$ \\
\hline Control & $129.48 \pm 10.21$ & $122.08 \pm 4.38$ & $105.37 \pm 3.24$ \\
\hline Dox & $85.74 \pm 6.77^{\mathrm{a}}$ & $89.13 \pm 4.02^{\mathrm{a}}$ & $70.12 \pm 11.47^{\mathrm{a}}$ \\
\hline$\%$ change $^{A}$ & $(-33.78 \%)$ & $(-26.99 \%)$ & $(-33.45 \%)$ \\
\hline Dox + GT & $103.96 \pm 12.38^{\mathrm{b}}$ & $124.25 \pm 5.37^{\mathrm{b}}$ & $72.42 \pm 11.48$ \\
\hline$\%$ change $^{\mathrm{B}}$ & $(+21.25 \%)$ & $(+39.40 \%)$ & $(+3.28 \%)$ \\
\hline Dox + Epi & $103.14 \pm 14.12^{\mathrm{b}}$ & $119.63 \pm 3.68^{b}$ & $64.09 \pm 18.75$ \\
\hline$\%$ change $^{\mathrm{B}}$ & $(+20.29 \%)$ & $(+34.22 \%)$ & $(-8.60 \%)$ \\
\hline
\end{tabular}

Data represented as a mean \pm SEM. The number of animals in each group is six.

${ }^{\mathrm{a}, \mathrm{b}}$ Significant difference in comparison with the corresponding normal control and Dox-administered groups ,respectively, at $p<0.05$.

$\mathrm{A}, \mathrm{B}$ Percentage of changes in relation to the normal control and Dox-administered groups, respectively.

GT: green tea aqueous extract; Epi: epicatechin.

decreasing the elevated mRNA expression of $\mathrm{NF}-\kappa \mathrm{B}$ relative to $\beta$-actin (Fig. 5).

\section{Histopathological and immunohistochemical findings}

The normal liver histological structure is shown in Figure 6. The hepatocytes are arranged in hepatic trabeculae that radiate from the central vein $(\mathrm{CV})$ forming sinusoids in between. The sinusoids are lined by Kupffer cells $(\mathrm{Kc})$ and endothelial cells. The photomicrograph of liver section showed organized architecture and integrity.

The liver of Dox-administered rats showed congested CVs, Kupffer cell proliferation as well as hyperemic sinusoids. There were mild strands of fibroblasts around the hepatocytes and cytoplasmic vacuolization of hepatocytes (Fig. 7; photomicrograph 7a). Fibrosis of hepatic capsule and vacuolization of hepatocytes were also noticed (Fig. 6; photomicrograph 7b) in addition to fibroplasia of the bile duct and vacuolization of hepatocytes (Fig. 7; photomicrograph 7c).

The treatment with green tea aqueous extract produced marked amelioration of Dox-induced liver histological deleterious changes. Mild vascular changes and few Kupffer cells activation and binucleated hepatocytes were noticed in the liver of Dox-administered rats.
The treatment of Dox-administered rats with epicatechin induced a remarkable amelioration of liver histological changes. Slight thickening of hepatic capsules and apparent normal hepatocytes were noticed in liver sections of Dox-administered animals treated with epicatechin (Fig. 9; photomicrographs 9a and 9b).

The immunohistochemical sections of COX-2 expression in normal rats depicted a weak immunohistochemical reaction for COX-2 in hepatocytes (Fig. 10; photomicrograph 10a). On the other hand, the liver of Dox-administered rats exhibited an evoked strong reaction in the form of brownish color in the cytoplasm of hepatocytes (Fig. 10; photomicrograph 10b). The liver of Doxadministered rats treated with green tea aqueous extract (Fig. 10; photomicrograph 10c) and epicatechin (Fig. 10; photomicrograph 10d) showed a weak expression of COX-2.

Immunohistochemical staining of caspase- 3 in liver of normal rat exhibited a weak expression of caspase-3 (Fig. 11; photomicrograph 11a). In contrast, the liver of Dox-administered rats showed a strong activated expression of caspase-3 represented by dense cytoplasmic brownish color (Fig. 11; photomicrograph 11b). On the other hand, Dox-administered rats treated with green tea aqueous extract (Fig. 11; photomicrograph 11c) and epicatechin (Fig. 11; photomicrograph 11d) exhibited a weak expression of caspase-3. 
P53

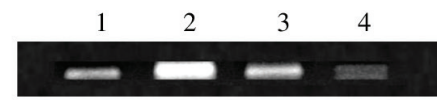

$\beta$-actin
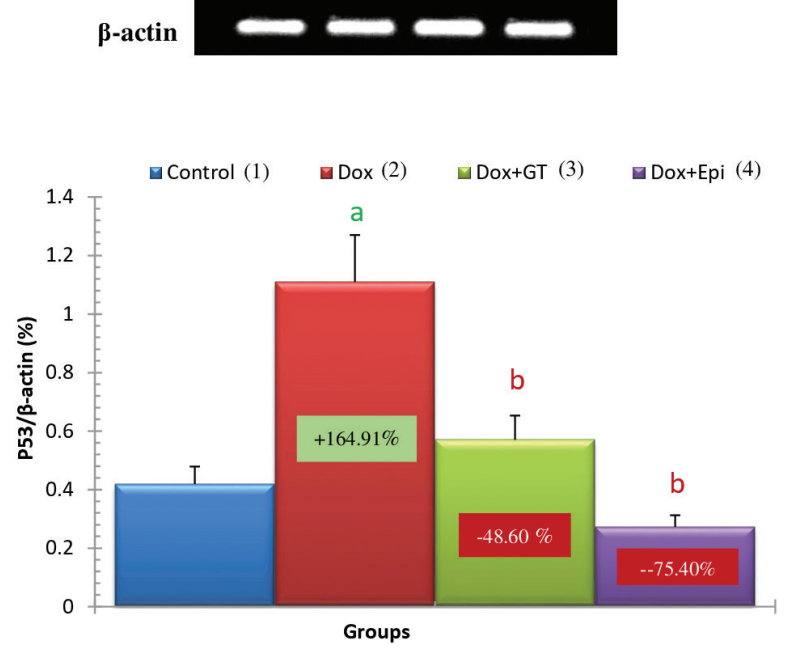

Figure 3. Effects of green tea aqueous extract and epicatechin on liver p53 mRNA expression relative to $\beta$-actin in Dox-administered rats. The number of detected samples in each group is three. ${ }^{\mathrm{a}, \mathrm{b}}$ Significant difference in comparison with the corresponding control and Doxadministered groups, respectively, at $p<0.05$. Percentage changes were calculated in relation to the normal control and Dox-administered groups, respectively. GT: green tea aqueous extract; Epi: Epicatechin.
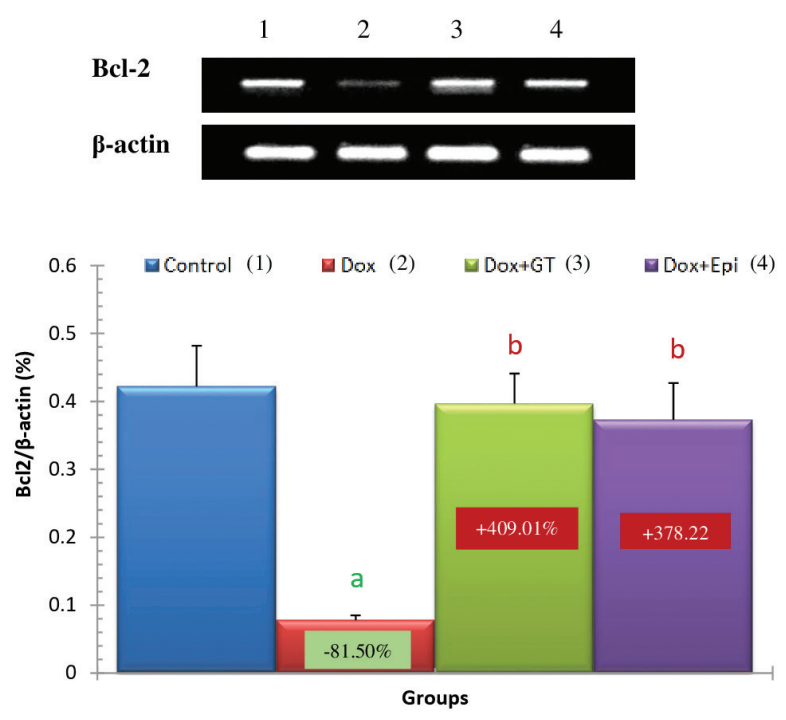

Figure 4. Effect of green tea aqueous extract and epicatechin on liver Bcl2 mRNA expression relative to $\beta$-actin in Dox-administered rats. The number of detected samples in each group is three. ${ }^{\mathrm{a}, \mathrm{b}}$ Significant difference in comparison with the corresponding control and Doxadministered groups, respectively, at $p<0.05$. Percentage changes were calculated in relation to the normal control and Dox-administered groups, respectively.

\section{DISCUSSION}

Dox is considered as one of the most potent anticancer agents. Its therapeutic application is limited due to its deleterious effects on normal tissues, such as the liver and heart (Ibrahim et al., 2010; Wang et al., 2012). However, the mechanisms of
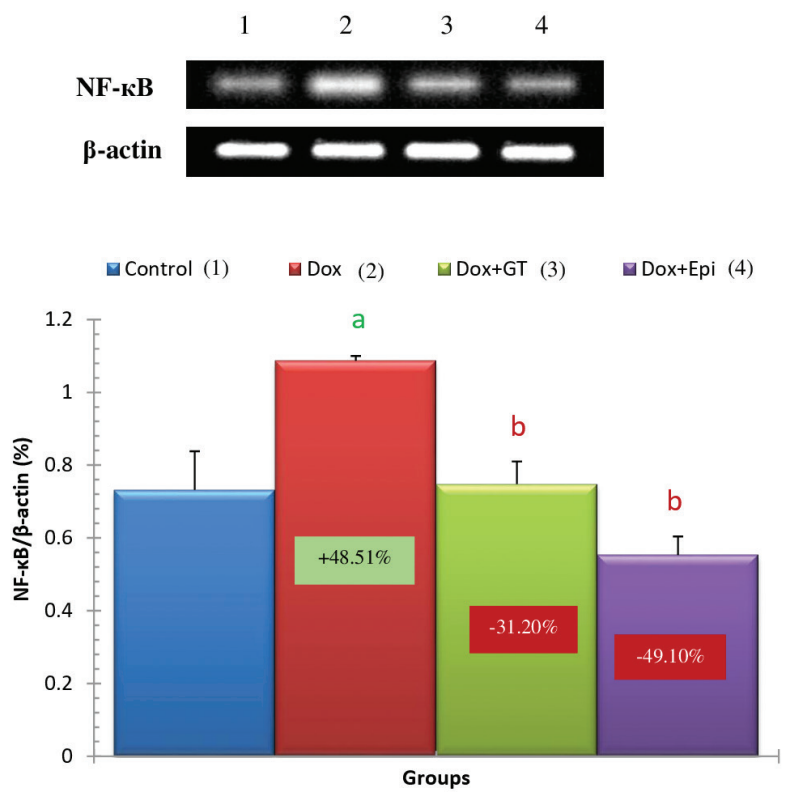

Figure 5. Effect of green tea aqueous extract and epicatechin on liver NF- $\kappa B$ mRNA expression relative to $\beta$-actin in Dox-administered rats. ${ }^{\mathrm{a}, \mathrm{b}}$ Significant difference in comparison with the corresponding control and Dox-administered groups, respectively, at $p<0.05$. Percentage changes were calculated in relation to the normal control and Doxadministered groups, respectively.

Dox-mediated cytotoxicity in normal tissues and cancer cells are different (Wang et al., 2012). In its mechanisms of action, Dox may act through DNA intercalation, membrane function alteration, and ROS formation (King and Perry, 2001). Dox is considerably metabolized in the liver (King and Perry, 2001); thereby, the liver is one of the organs that are mostly affected by Dox toxicity.

It is worth mentioning from many previous publications that Dox is considered as the most toxic anthracyclines and causes weight loss (Danz et al., 2009; Panjrath et al., 2007; SayedAhmed et al., 2010). For this reason, overdosage and long-term administration of this drug causes toxicity and death.

The main toxic and deleterious effects on hepatocytes include disruption of electron transport and oxidative stress and arrest cell cycle of hepatocytes (Kassner et al., 2008; Zhao et al., 2012). To reduce the toxic and side effects of Dox, various strategies were reported (EL-Hak et al., 2018; Jabłońska-Trypuć et al., 2018). The newly developed chemotherapeutic drugs often cause many side effects that restrict their use which are mostly oxidative stressdependent (Ahmed and Abdella, 2010). Therefore, recent studies hypothesized that the combination of the chemotherapeutic drug such as Dox together with a potent natural antioxidant may be the appropriate approach to mitigate the toxic side effects of this kind of drugs (Ahmed and Abdella, 2010; Injac et al., 2008).

The present study revealed that Dox injected weekly at dose $4 \mathrm{mg}$ Dox $/ \mathrm{kg}$ b.w. through intraperitoneal route for 6 weeks induced hepatotoxicity which was biochemically manifested by a significant elevation of serum ALT, AST, ALP, and GGT activities and bilirubin level in addition to a significant lowering in serum level of albumin. These changes run parallel with Ahmed et al. (2013) and Injac et al. (2008) who attributed the elevation in the 


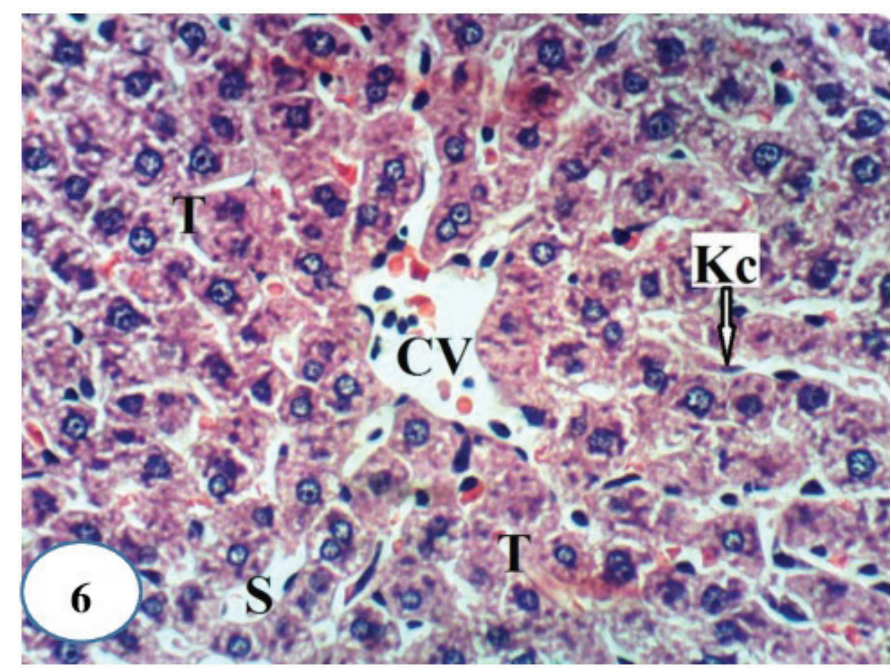

Figure 6. A photomicrograph of liver section of normal rats showing a normal histological structure of hepatic lobule and depicting a $\mathrm{CV}$, hepatic strands or trabeculae (T) with sinusoids (S) and Kupffer cells (Kc) inbetween $(\mathrm{H} \& \mathrm{E} \times 400)$.

serum enzyme activities to their excess leakage from degenerated hepatocytes and damage in bile ductular cells membranes as a result of toxicity. The significant decrease in serum albumin level in Dox-administered rats is in accordance with EL-Maraghy et al. (2009) who attributed this change to alterations in protein and free amino acid metabolism and their synthesis in the injured hepatocytes and/or increased protein degradation. On the other hand, the elevation in the total bilirubin level in serum of Dox-administered rats may be due to blockage of bile canaliculi as a result of inflammatory cells infiltration, fibroblast proliferation and fibrosis in the portal areas, and/or may be owing to regurgitation of direct (conjugated) bilirubin from the necrotic liver cells to sinusoids (Ahmed, 2001; Deepa and Varalakshmi, 2003; Saad et al., 2001).

The previous deleterious biochemical alterations of liver biomarkers in serum of Dox-administered rats in the current study were accompanied with a remarkable increase in liver LPO and a significant suppression in the liver levels of non-enzymatic antioxidant (GSH) as well as enzymatic antioxidants (SOD, GPx, and GST). These results are in concurrence with those obtained by several authors (Abd El-Aziz et al., 2001; Ahmed et al., 2013; Balachandar et al., 2003; Kalender et al., 2005; Patel et al., 2010; Yagmurca et al., 2007) who stated that one of the most convincing hypotheses of hepatic injury due to Dox injection is the ability of the drug to produce excess free radicals and lipid peroxides and to suppress free radical scavenging capacity and antioxidant defensive mechanism.

Histopathological investigation of liver sections of Dox-administered rats in the present study supported the previous biochemical results. The liver of Dox-administered rats showed congested CVs, hyperemic sinusoids, Kupffer cell multiplication, strands of fibroblasts around the hepatocytes, cytoplasmic vacuolization of hepatocytes, fibrosis of hepatic capsule, and periductal fibroblastic proliferation around the bile ductules. These results are in concordance with Yagmurca et al. (2007) who reported

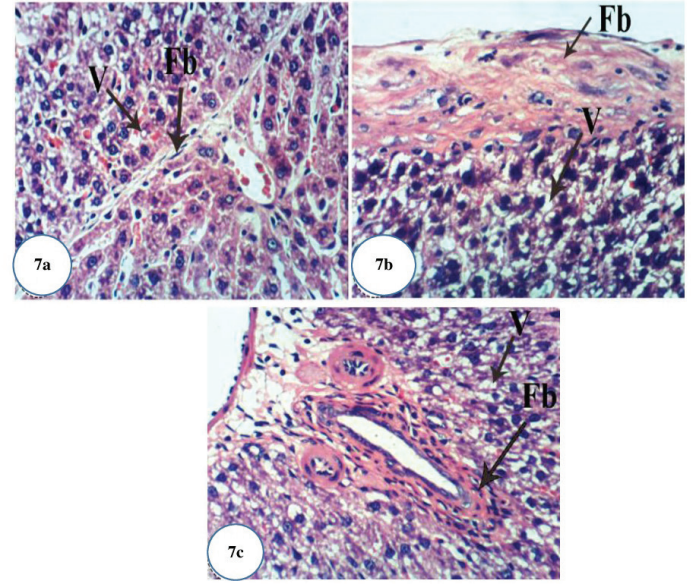

Figure 7. Photomicrographs of liver section of Doxadministered rats showing: (a) strands of fibroblasts $(\mathrm{Fb})$ around the hepatocytes and vacuolization $(\mathrm{V})$ of hepatocytes $(H \& E \times 400)$; (b) fibrosis of hepatic capsule and vacuolization (V) of hepatocytes (H\&E $\times 400)$; and (c) fibroplasia of bile duct and vacuolization $(\mathrm{V})$ of hepatocytes $(\mathrm{H} \& \mathrm{E} \times 400)$.

destructive damage of hepatocytes, necrotic foci, blood congestion, and proliferation of bile canaliculi in Dox-supplemented rats.

Antioxidants obtained from natural sources and plants represent a logical treatment strategy for therapy of liver diseases. In this regard, there are many plant-derived chemicals with powerful antioxidant properties that may serve as primary compounds for developing novel hepatoprotective drugs (Girish and Pradhan, 2012; Pradhan and Girish, 2006). Green tea and its constituting catechins are best known for their free radical scavenging capabilities, which have led to their evaluation in a number of diseases associated with exacerbated production of ROS, such as diabetes mellitus, cancer, neurodegenerative diseases, and cardiovascular disorders. Several epidemiological and meta-analysis studies as well as studies in animal models have depicted that green tea can afford protection against various types of cancers including breast, skin, lung, and prostate cancers (Mukhtar and Ahmad, 2000; Yang et al., 2002). The epicatechin as one of the major constituent of green tea is considered as one of the most potent antioxidant component of catechin (Ishige et al., 2001) due to its higher free radical scavenging activity (Kostyuk et al., 2004) and its greater bioavailability over other catechin components (Baba et al., 2001).

In conduction with the previous studies, the treatment of Dox-administered rats with green tea aqueous extract and epicatechin potentially alleviated the raised serum ALT, AST, and ALP enzyme activities and bilirubin level. The lowered serum albumin level was detectably increased in Dox-administered rats treated with green tea aqueous extract and epicatechin. These improvements in serum biomarkers of liver function were associated with potential amendment of liver integrity and architecture and amelioration of Dox-induced deleterious hispathological changes. These alterations are in concordance with the previously published report of Mandziuk et al. (2015) who depicted that Dox-induced inflammation, eosinophilic degeneration, and interstitial edematous changes were markedly reduced by green tea. The ameliorative effects of green tea 

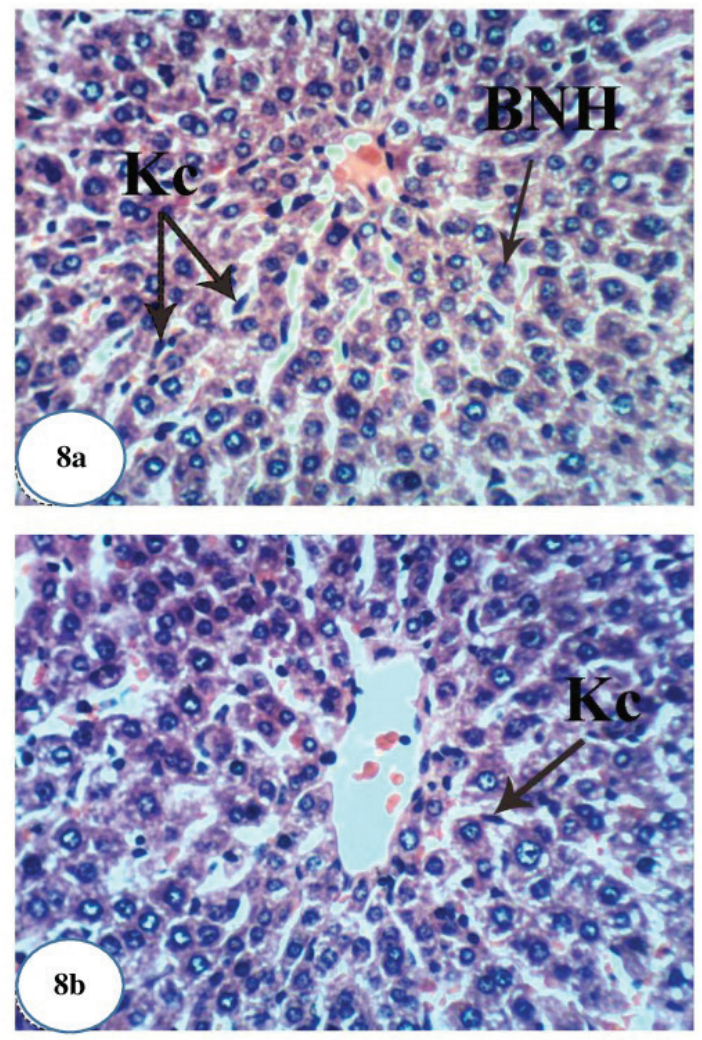

Figure 8. Photomicrographs of liver sections of Doxadministered rats treated with green tea. ( $a$ and b) Marked recovery of normal structure except the presence of few Kupffer cells $(\mathrm{Kc})$ activation and binucleation of hepatocytes $(\mathrm{BNH})(\mathrm{H} \& \mathrm{E} \times 400)$.

aqueous extract and epicatechin may be attributed to the potentiation of the antioxidant defense system and suppression of ROS generation. It is important here to mention that the ALP activity was more decreased in the Dox-administered rats treated with green tea aqueous extract and epicatechin than the normal control. The decrease lower than the normal due to treatment with green tea may be attributed to the presence of epigallocatechin gallate and gallocatechin gallate, which have inhibitory effects on phosphatases (Okamoto et al., 2003) due to the presence of galloyl moiety in the structure. The epicatechin may also have inhibitory effects on ALP activity. The serum activity of GGT, responsible for extracellular GSH, was significantly increased as a result of treatment of Dox-administered rats with epicatechin. This up-regulation of GGT activity may be attributed in the light of suggestion of Chinta et al. (2006) who hypothesized that increased GGT activity may be an adaptive response to the loss of glutathione to conserve intracellular GSH content and results in a compensatory effect on mitochondrial complex I activity rather than in its inhibition and decrease following improvement of hepatobiliary function.

In the present study, the treatment of Dox-injected rats with green tea aqueous extract and epicatechin reduced liver LPO and increased the liver GSH level and GPx, GST, and SOD enzyme activities. These antioxidative features of green tea and its catechin have been reported in previous in vivo studies, which demonstrated that dietary intake of green tea catechins can improve total
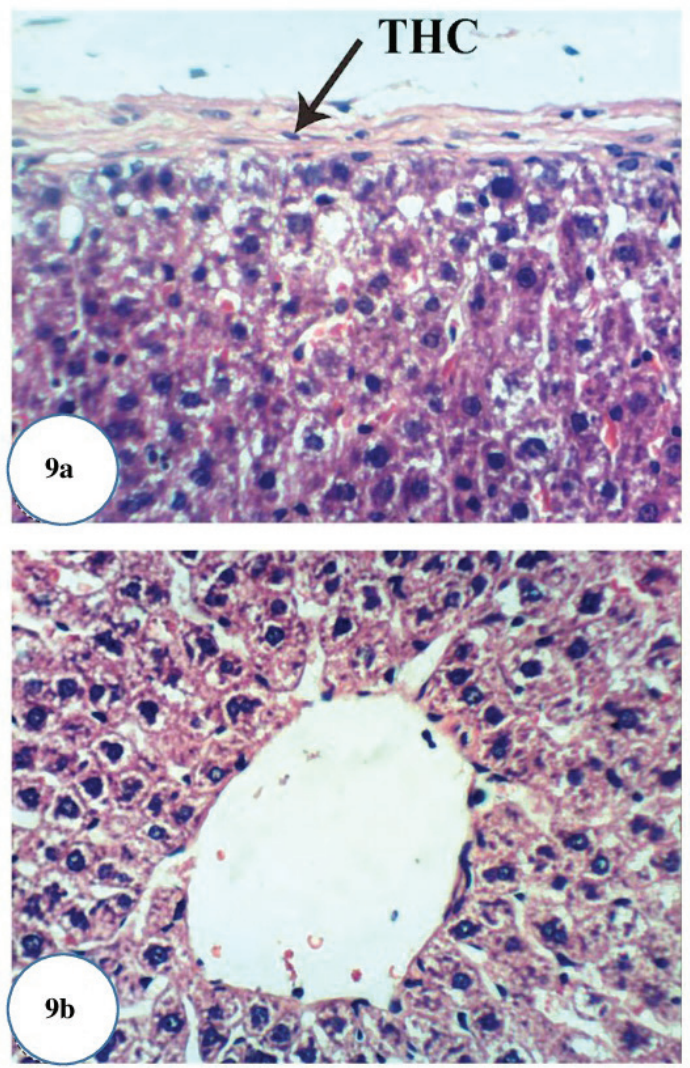

Figure 9. Photomicrographs of liver sections of Doxadministered rats treated with epicatechin. (a) Slight thickening of hepatic capsule $(\mathrm{THC})(\mathrm{H} \& \mathrm{E} \times 400)$ and $(\mathrm{b})$ apparent normal hepatocytes $(\mathrm{H} \& \mathrm{E} \times 400)$. antioxidant capacity and can decrease the level malondialdehyde (MDA), as a biomarker of LPO, in the rat's liver, blood, and brain (Skrzydlewska et al., 2000). In another study, Quine and Raghu (2005) showed that epicatechin supplementation at a dose of 15 and $30 \mathrm{mg} / \mathrm{kg}$ b.w. in diabetic rats produced a significant decrease in MDA levels and increase in GSH concentration and SOD, GPx, and catalase (CAT) activities in the liver. In the same regard, Rizvi et al. (2005) had revealed that epicatechin treatment produced an elevation in GSH content in red blood cells of both normal and type 2 diabetic subjects. Rizvi and Zaid (2001) have also stated that tea catechins (epicatechin is being one of the components) protect type 2 diabetic red blood cells from tert-butyl hydroperoxide-induced oxidative stress. Moreover, Cuevas et al. (2009) found that epicatechin produced a significant decrease in LPO and reactive oxygen species in amyloid- $\beta$-treated rats. Mohamed et al. (2011) reported that SOD, CAT, and GPx in the brain tissues in Dox-administered rats were normalized and the elevated level of MDA was decreased upon using epicatechin supplementation. The strong free radical scavenging activity of epicatechin might be due to its antioxidant property as a result of the presence of adjacent hydroxyl (OH) groups on the same ring (Cuevas et al., 2009; Haque et al., 2006; Mohamed et al., 2011; Rahman, 2016). In the present study, the chemical analysis of green tea extract indicated the presence of many free radical scavenging constituents including gallic acid, (-)-gallocatechin, (-)-gallocatechin, (-)-epicatechin, 


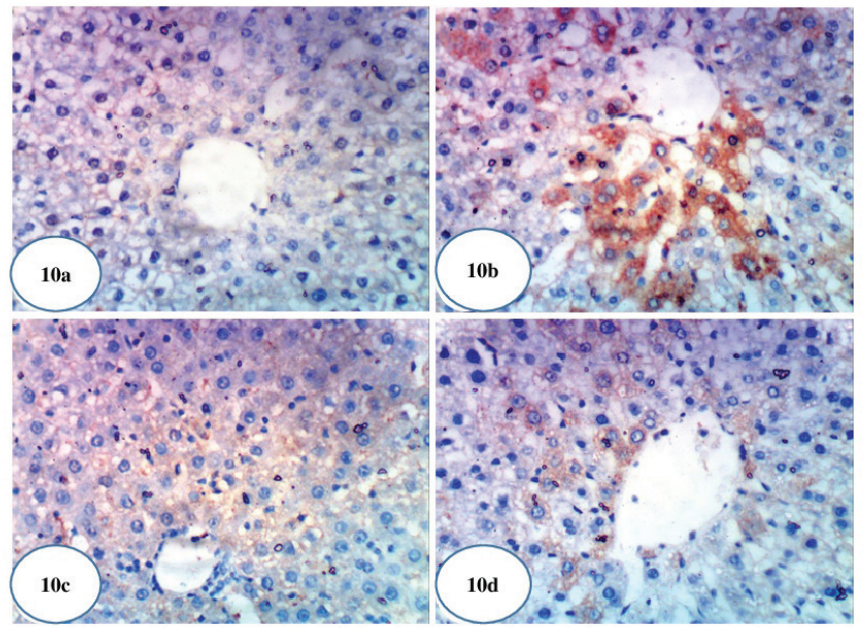

Figure 10. Photomicrographs of immunohistochemical stained liver sections for COX-2 expression detection. (a) A photomicrograph of immunohistochemical staining of COX-2 in liver of normal control rat showing a weak expression of COX-2 (×400). (b) A photomicrograph of immunohistochemical staining of COX-2 in liver of Dox-administered rats showing a strong stimulated expression of COX-2 (immunopositivity indicated by brownish color) $(\times 400)$. (c) A photomicrograph of immunohistochemical staining of COX-2 in liver of Dox-administered rats treated with green tea showing a weak expression of COX-2 (immunopositivity indicated by brownish color) $(\times 400)$. (d) A photomicrograph of immunohistochemical staining of COX-2 in liver of Dox-administered rats treated with epicatechin showing a weak expression of COX-2 (immunopositivity indicated by brown color) $(\times 400)$.

(-)-epigallocatechin, (-)-epigallocatechin gallate, (-)-gallocatechin gallate, (-)-epicatechin gallate, (-)-catechin gallate, and caffeine.

Tumor marker AFP, a specific glycoprotein secreted from fetal liver and yolk sac, that rapidly falls few weeks after birth (Patil et al., 2013), is the most reliable serum marker for the diagnosis of hepatocellular carcinoma (HCC) (Wen-Jun et al., 2013). There was a marked elevation in serum AFP level in rats injected with Dox alone. This finding is consistent with the previous report which revealed that the injection of Dox to rats resulted in the increase of serum AFP level reflecting increased probability of and susceptibility to HCC (Kim et al., 2010). On the other hand, the Dox-injected groups treated with green tea and epicatechin showed an improvement in the serum level of AFP reflecting their potent anti-cancer and hepatoprotective effects. In agreement with the previous publication of Abozalam et al. (2016), Nakagami (2004), Rani et al. (2014), Shanmugam et al. (2017), and Tadesse et al. (2015) who reported the anticancer and antioxidant effects of green tea and epicatechin.

In the present study, the apoptotic mediators, p53, and caspase 3 expressions in liver were markedly elevated in Dox-administered rats while expression of anti-apoptotic marker Bcl-2 was significantly lowered. The treatment of Doxadministered rats with green tea aqueous extract and epicatechin prevented these alterations. The augmented apoptosis in Doxadministered rats may be attributed to the activated oxidative stress. This attribution was supported by Patel et al. (2010) who stated that oxidative stress has been implicated as a contributor factor to various forms of cell death, involving a specific inducer of apoptosis. In turn, the reduced apoptosis in the liver as a result of the treatment of Dox-injected rats with green tea aqueous
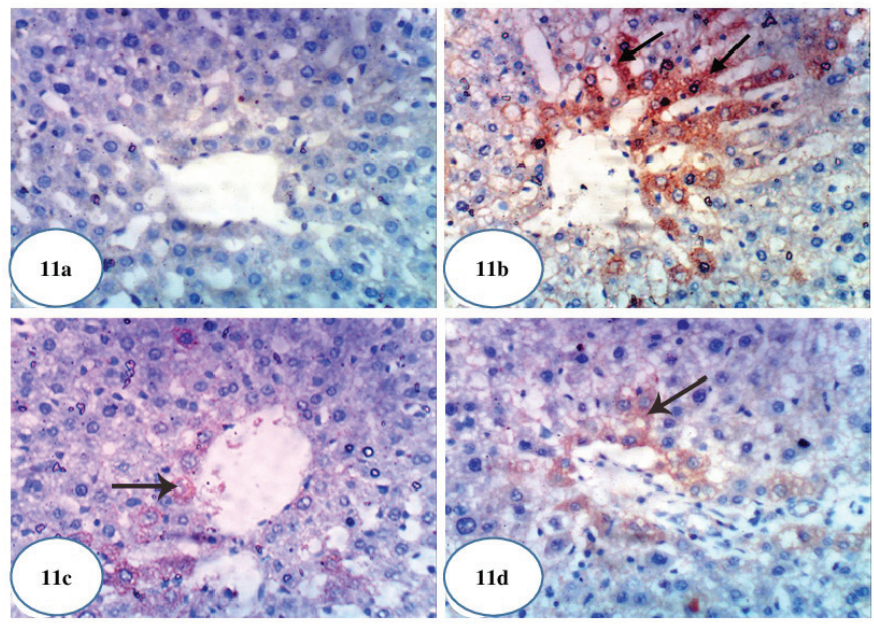

Figure 11. Photomicrographs of immunohistochemical stained liver sections for caspase-3 expression detection. (a) A photomicrograph of immunohistochemical staining of caspase-3 in liver of normal control rat showing a weak expression of caspase-3 $(\times 400)$. (b) A photomicrograph of immunohistochemical staining of caspase-3 in liver of Dox-administered rats showing a strong augmented expression of caspase-3 (immunopositivity indicated by brownish color) $(\times 400)$. (c) A photomicrograph of immunohistochemical staining of caspase-3 in liver of Dox-administered rats treated with green tea showing a weak expression of caspase-3 (immunopositivity indicated by brownish color) $(\times 400)$. (d) A photomicrograph of immunohistochemical staining of caspase-3 in liver of Dox-administered rats treated with epicatechin showing a weak expression of caspase-3 (immunopositivity indicated by brownish color) $(\times 400)$.

extract and epicatechin may result secondary to the suppressed oxidative stress and enhanced antioxidant defense system. This suggestion runs parallel with Spencer et al. (2001) who evidenced that 3'-O-methyl epicatechin inhibits $\mathrm{H}_{2} \mathrm{O}_{2}$-induced cell death and that the mechanism involves attenuation of caspase- 3 activity as an apoptotic marker.

To assess the effect on the inflammatory status, the levels of serum TNF- $\alpha$ and IL-4 were determined by ELISA, liver NF- $\kappa \mathrm{B}$ mRNA expression was assayed by RT-PCR, and COX-2 was assayed by immunohistochemical technique.

In the current study, the level of pro-inflammatory cytokine TNF- $\alpha$ in serum was significantly elevated in Dox-administered rats while the level of anti-inflammatory cytokine IL-4 was significantly decreased reflecting the preponderance of T helper 1 (Th1) and the presence of elevated Th1: T helper 2 (Th2) cell ratio. These data are in concurrence with Shankar et al. (2007) who found that injection of Dox augments a peripheral increase in the cytokine TNF- $\alpha$, which stimulates several inflammatory pathways. As indicated by Tangpong et al. (2006), TNF- $\alpha$ induces mitochondrial malfunction by its downstream consequences, leading to further increase in cytochrome $\mathrm{C}$ release, oxidative stress, caspase 3 activity, and TUNEL-positive cell death, all of which are implicated as inducers of apoptosis following Dox injection. On the other hand, IL-4 was reported to inhibit multiple functions of activated macrophages, including macrophage production of TNF- $\alpha$ and interleukin-1 $\beta$ (IL-1 $1 \beta$ ), and the macrophage secretion of reactive oxygen intermediates and up-regulate expression of interleukin-1 (IL-1) receptor antagonist (Abramson and Gallin, 1990; Hart et al., 1989; Vannier et al., 1992). It also activates macrophage 15 lipoxygenase activity, which 
may suppress the synthesis of pro-inflammatory leukotriene B4 (LTB4) (Katoh et al., 1994). The treatments of Dox-administered rats with green tea aqueous extract and epicatechin, in the present study, improved the deteriorations in both TNF- $\alpha$ and IL-4 levels reflecting dominance of Th2 cells. Thus, both green tea aqueous extract and epicatechin may have potent anti-inflammatory effects by activating the production Th2 cytokines and suppressing the activity of Th1 cells.

It was also evidenced in the present study that the liver $\mathrm{NF}-\kappa \mathrm{B}$ and COX-2 expressions were remarkably increased in Dox-administered rats and were recovered toward normal levels as a result of treatments of Dox-administered rats with green tea aqueous extract and epicatechin. These results are in concurrence with many previous reports. Lagha and Grenier (2015) found that black and green tea polyphenols suppress the inflammatory response of monocytes/macrophages mediated by Fusobacterium nucleatum ( $F$. nucleatum). They also first stated that the black and green tea extracts, theaflavins, (-)-epigallocatechin-3-gallate (EGCG) reduce the NF- $\kappa \mathrm{B}$ activation induced by $F$. nucleatum in monocytes. It is also relevant here to mention that NF- $\kappa \mathrm{B}$ is a key regulator of genes coding for inflammatory mediators including of interleukin- $1 \beta$ (IL-1 $\beta$ ), TNF- $\alpha$, IL-6, and C-X-C Motif Chemokine Ligand 8 (CXCL8) by macrophages (Lagha and Grenier, 2015). Many other publications revealed the inhibitory effects of EGCG, which is a major component of green tea on NF- $\mathrm{BB}$ activation as well as TNF- $\alpha$ and COX-2 expression (Aggarwal and Shishodia, 2006; Gupta et al., 2004; Shankar et al., 2008; Shimizu et al., 2004). In the same way, Mohamed et al. (2011) reported that the treatment with epicatechin prior to Dox in rats significantly prevented the increase in TNF- $\alpha$, iNOS, and NF- $\kappa$ B expressions.

In conclusion, the $C$. sinensis aqueous extract and epicatechin have potent preventive effects against Dox-induced hepatotoxicity. The suppression of oxidative stress, the enhancement of antioxidant defense system, the modulatory effects of inflammatory signaling pathways, and anti-apoptotic actions all are implicated to prevent the Dox-induced hepatotoxicity and to improve the liver architecture and integrity. Thus, Camellia sinesis aqueous extract and epicatechin may be useful substances for patients treated with Dox.

\section{ABBREVIATIONS}

AFP: alpha-fetoprotein; ALP: alkaline phosphatase; ALT: alanine transaminase; AST: aspartate transaminase; b.w.: body weight; kg: kilogram; Bcl2: B-cell lymphoma 2; BNH: binucleation of hepatocytes; CAT: catalase; CCAC: Canadian Council on Animal Care; CMC: carboxymethyl cellulose; COX-2: cyclooxygenase-2; CV: central vein; Dox: Doxorubicin; $\mathrm{Fb}$ : fibroblasts; GGT: gamma glutamyl tansferase; GPx: glutathione peroxidase; GSH: glutathione; SEM: standard error mean; GST: glutathione-S-transferase; H\&E: Haematoxylin and Eosin; i.p.: intraperitoneally; IL-1 $\beta$ : interleukin-1 $\beta$; IL-4: interleukin-4; Kc: Kupffer cells; LPO: lipid peroxidation; LTB4: leukotriene B4; MDA: malondialdehyde; NF-кB: nuclear factor-kappa B cells; p53: protein 53; ROS: reactive oxygen species; RT-PCR: reverse transcriptase-polymerase chain reaction; $\mathrm{S}$ : sinusoids; SOD: superoxide dismutase; T: trabeculae; Th1: T helper 1; Th2: $\mathrm{T}$ helper 2; THC: thickening of hepatic capsule; TNF- $\alpha$ : tumor necrosis factor-alpha; $\mathrm{V}$ : vacuolization.

\section{ACKNOWLEDGMENTS}

The authors deeply thank Prof. Dr. K. A. Ahmed, Professor of Histopathology, Pathology Department, Faculty of Veterinary Medicine, Cairo University, Giza, Egypt, for his help in examining and reading the histological and immunohistochemical stained sections.

\section{CONFLICT OF INTEREST}

The authors declare that they have no conflict of interest.

\section{FINANCIAL SUPPORT}

The work was partially funded by Faculty of Science, Beni-Suef University, Beni-Suef, Egypt.

\section{REFERENCES}

Abd El-Aziz MA, Othman AI, Amer M, El-Missiry MA. Potential protective role of angiotensin-converting enzyme inhibitors captopril and enalapril against adriamycin-induced acute cardiac and hepatic toxicity in rats. J Appl Toxicol, 2001; 21:469-73.

Abozalam SB, Salama AA, Arbid MS, Ain Shoka AA, Abd El-Latif HA. Effect of barley, green tea and doxorubicin against $\mathrm{N}$-dimethylnitrosamine induced hepatorenal toxicity in rats. Curr Sci Internat, 2016; 5:386-99.

Abramson SL, Gallin JI. IL-4 inhibits superoxide production by human mononuclear phagocytes. J Immunol, 1990; 144:625-30.

Aggarwal BB, Shishodia S. Molecular targets of dietary agents for prevention and therapy of cancer. Bioch Pharmacol, 2006; 71:1397-421.

Ahmed OM. Histopathological and biochemical evaluation of liver and kidney lesions in streptozotocin diabetic rats treated with glimepiride and various plant extracts. J Union Arab Biol, 2001; 16A:585-625.

Ahmed OM. Antihyperglycemic effects of water extract of Ulva lactuca and its polysaccharides in nicotinamide-streptozotocin-induced diabetic rats. Egypt J Zool, 2010; 54:273-97.

Ahmed OM, Abdul-Hamid MM, El-Bakry AM, Mohamed HM, Abdel Rahman FS. Effects of green tea infusion and epicatechin on doxorubicin-induced renocardiotoxicity in male albino rats. IJPSR, 2019; 10(5):1000-14.

Ahmed OM, Ashour MB, Fahim HI, AbouZid SF, Ahmed RG, Abdel Gaid MA. Punica granatum mitigates 7, 12-dimethylbenz [A] anthracene and $\mathrm{CCl} 4$-induced oxidative stress and hepatic precancerous lesions in Wistar rats. Indo Am J Pharm Res, 2016; 6(09):6493-510.

Ahmed OM, Hozayen WG, Abo Sree HT. Effects of ethanolic purslane shoot and seed extracts on doxorubicin-induced hepatotoxicity in albino rats. Life Sci J, 2013; 10(4):67-74.

Ahmed OM, Hassan MA, Abdel-Twab SM, Abdel Azeem MN. Navel orange peel hydroethanolic extract, naringin and naringenin have anti-diabetic potentials in type 2 diabetic rats. Biomed Pharmacother, 2017; 94:197-205.

Ahmed RR, Abdella EM. Modulatory effects of rosemary leaves aqueous extract on doxorubicin-induced histological lesions, apoptosis and oxidative stress in mice. Iran J Cancer Prev, 2010; 3(1):1-22.

Alappat B, Sarna JA, Truong C. Anticancer and antioxidant properties of flavored green tea extracts. J Agric Life Sci, 2015; 2:15-24.

Al-Hilfy JHY. Effect of green tea aqueous extract on body weight, glucose level, and kidney functions in diabetic male albino rats. J Al-Nahrain Univ, 2012; 15(3):161-6.

Ashok I, Sheeladevi R. Biochemical responses and mitochondrial mediated activation of apoptosis on long-term effect of aspartame in rat brain. Redox Biol, 2014; 2:820-31.

Asiri YA. Probucol attenuates cyclophosphamide-induced oxidative apoptosis, p53 and Bax signal expression in rat cardiac tissues. Oxid Med Cell Longev, 2010; 3:308-16.

Baba S, Osakabe N, Natsume M, Muto YT, Takizawa TJ, Terao J. In vivo comparison of the bioavailability of (+)-catechin, 
(-)-epicatechin and their mixture in orally administered rats. J Nutr, 2001; 131:2885-91.

Bai P, Ye H, Xie M, Saxena P, Zulewski H, Hamri GC, Djonov V, Fussenegger M. A synthetic biology-based liver-protection device preventing acute liver injuries. J Hepatol, 2016; 65(1):84-94.

Balachandar AV, Malarkodi KP, Varalakshmi P. Protective role of DL alpha-lipoic acid against adriamycin-induced cardiac lipid peroxidation. Hum Exp Toxicol, 2003; 22:249-54.

Bancroft JD, Stevens A, Turner DR. Theory and practice of histological techniques. 4th edition, Churchil Living Stone, New York, London, San Francisco, Tokyo, p. 766, 1996.

Beutler E, Duren O, Kelly BM. Improved method for the determination of blood glutathione. J Lab Clin Med, 1963; 61(5):882-8.

Canadian Council on Animal Care (CCAC). Guide to the care and use of experimental animals. CCAC, Ottawa, ON, Canada, pp. 1-298, 2010.

Chinta SJ, Kumar JM, Zhang H, Forman HJ, Andersen JK. Up-regulation of gamma-glutamyl transpeptidase activity following glutathione depletion has a compensatory rather than an inhibitory effect on mitochondrial complex I activity: implications for Parkinson's disease. Free Radic Biol Med, 2006; 40(9):1557-63.

Chomzynski P, Sacchi N. Single-step method of RNA isolation by acid guanidinium thiocyanate-phenol-chloroform extraction. Annu Rev Biochem, 1987; 162:156-9.

Cuevas E, Limón D, Pérez-Severiano F, Díaz A, Ortega L, Zenteno E, Guevara J. Antioxidant effects of epicatechin on the hippocampal toxicity caused by amyloid-beta 25-35 in rats. Eur J Pharmacol, 2009; 616(1-3):122-7.

Cui Y, Morgenstern H, Greenland S, Tashkin DP, Mao JT, Cai L, Cozen W, Mack TM, Lu QY, Zhang ZF. Dietary flavonoid intake and lung cancer - a population-based case-control study. Cancer, 2008; 112(10); 2241-2248.

Danz ED, Skramsted J, Henry N, Bennett JA, Keller RS. Resveratrol prevents doxorubicin cardiotoxicity through mitochondrial stabilization and the Sirt1 pathway. Free Radic Biol Med, 2009; 46:158997.

Deepa PR, Varalakshmi P. Protective effect of low molecular weight heparin on oxidative injury and cellular abnormalities in adriamycin-induced cardiac and hepatic toxicity. Chemico Biol Interact, 2003; 146(2):201-10.

Doumas BT, Watson WA, Biggs HG. Determination of serum albumin. J Clin Chem Acta, 1971; 31:87-9.

EL-Hak HNG, Moustafa AA, Mansour SR. Influence of injection mode and antioxidant dietary on the toxicity of Doxorubicin as a chemotherapy drug. Gastroenterol Hepatol, 2018; 9(6):255-7.

EL-Maraghy SA, Rizk SM, El-Sawalhi MM. Hepatoprotective potential of crocin and curcumin against iron overload induced biochemical alterations in rat. Afr J Biochem Res, 2009; 3(5):215-21.

Geoffrey KK, John KM, Naomi M, Simon KM. Qualitative phytochemical screening of Camellia sinensis and Psidium guajava leave extracts from Kericho and Baringo Counties. Int J Adv Biotechnol Res, 2014; 5(3):506-12.

Gendler S. ${ }_{\gamma}$ GT. In: Kaplan A, Pesce AJ (eds.). Methods in clinical chemistry. The C.V. Mosby Co, St Louis, Toronto, Princeton, pp. 1120-3, 1984.

Giorno RA. Comparison of two immunoperoxidase staining methods based on the avidin-biotin interaction. Diagn Immunol, 1984; 2:161-6.

Girish C, Pradhan SC. Hepatoprotective activities of picroliv, curcumin, and ellagic acid compared to silymarin on carbon-tetrachloride induced liver toxicity in mice. J Pharmacol Pharmacother, 2012; 3(2):149 55.

Gupta S, Hastak K, Afaq F, Ahmad N, Mukhtar H. Essential role of caspases in epigallocatechin-3-gallatemediated inhibition of nuclear factor kappaB and induction of apoptosis. Oncogene, 2004; 23:2507-22.

Haque AM, Hashimoto M, Katakura M, Tanabe Y, Hara Y, Shido O. Long term administration of green tea catechins improves spatial cognition learning ability in rats. J Nutr, 2006; 136:1043-7.

Hart PH, Vitti GF, Burgess DR, Whitty GA, Piccoli DS, Hamilton JA. Potential anti-inflammatory effects of interleukin 4: suppression of human monocyte tumor necrosis factor alpha, interleukin 1, and prostaglandin E2. Proc Natl Acad Sci USA, 1989; 86:3803-7.

Hussein AM, Ahmed OM. Regioselective one-pot synthesis and anti-proliferative and apoptotic effects of some novel tetrazolo[1,5-a] pyrimidine derivatives. Bioorg Med Chem, 2010; 18:2639-44.

Ibrahim SS, Barakat MA, Helmy HS. Modulating effect of carvedilol on doxorubicin-induced cardiomyopathy and hepatic damage. $\mathrm{J}$ Am Sci, 2010; 6:20-32.

Injac R, Perse M, Obermajer N, Djordjevic-Milic V, Prijatelj M, Djordjevic A, Cerar A, Strukelj B. Potential hepatoprotective effects of fullerenol $\mathrm{C}_{60}(\mathrm{OH})_{24}$ in Doxorubicin-induced hepatotoxicity in rats with mammary carcinomas. Biomaterials, 2008; 29(24-25):3451-60.

Ishige K, Schubert D, Sagara Y. Flavonoids protect neuronal cells from oxidative Stress by three distinct mechanisms. Free Radic Biol Med, 2001; 30:433-46.

Jabłońska-Trypuć A, Krętowski R, Kalinowska M, Świderski G, Cechowska-Pasko M, Lewandowski W. Possible mechanisms of the prevention of doxorubicin toxicity by cichoric acid - antioxidant nutrient Nutrients, 2018; 10(44):1-21. $1938 ; 297: 81$

Jendrassik L, Grof P. Total and direct bilirubin. Biochem Z,

Kaiserova H, Simunek T, Sterba M, den Hartog GJ, Schroterova L, Popelová O, Geršl V, Kvasničková E, Bast A. New iron chelators in anthracycline-induced cardiotoxicity. Cardiovasc Toxicol, 2007; 7(2): 145150

Kalender Y, Yel M, Kalender S. Doxorubicin hepatotoxicity and hepatic free radical metabolism in rats. The effects of vitamin $\mathrm{E}$ and catechin. Toxicology, 2005; 209(1):39-45.

Kanwar J, Taskeen M, Mohammad I, Huo C, Chan TH, Dou QP. Recent advances on tea polyphenols. Front Biosci (Elite Ed), 2012; $4: 111-31$.

Kar M, Mishra D. Catalase, peroxidase, and polyphenoloxidase activities during rice leaf senescence. Plant Physiol, 1976; 57(2):315-9.

Karaman A, Fadillioglu E, Turkmen E, Tas E, Yilmaz Z. Protective effects of leflunomide against ischemia reperfusion injury of the rat liver. Pediatr Surg Int, 2006; 22:428-34.

Kassner N, Huse K, Martin HJ, Gödtel-Armbrust U, Metzger A, Meineke I, Brockmöller J, Klein K, Zanger UM, Maser E, Wojnowski L. Carbonyl reductase 1 is a predominant Doxorubicin reductase in the human liver. Drug Metab Dispos, 2008; 36:2113-20.

Katoh T, Lakkis FG, Makita N, Badr KF. Co-regulated expression of glomerular 12/15-lipoxygenase and interleukin-4 mRNAs in rat nephrotoxic nephritis. Kidney Int, 1994; 46:341-9.

Khan N, Mukhtar H. Cancer and metastasis: prevention and treatment by green tea. Cancer Metastasis Rev, 2010; 29:435-45.

Kim JD, Bae SH, Park JY, Han KH, Woo HY, Choi JY, Yoon SK, Jang BK, Hwang JS, Kim SG. A comparative study of high-dose hepatic arterial infusion chemotherapy and trans-arterial chemoembolization using doxorubicin for intractable, advanced hepatocellular carcinoma. Korean J Hepatol, 2010; 16(4):355-61.

King PD, Perry MC. Hepatotoxicity of chemotherapy. Oncologist, 2001; 6:162-76.

Kostyuk VA, Potapovich AI, Strigunova EN, Kostyuk TV, Afanas'ev IB. Experimental evidence that flavonoid metal complexes may act as mimics of superoxide dismutase. Arch Biochem Biophys, 2004; 428:204-8.

Kuznetsova AV, Raimund M, Albert A, Valdur S, Michael G. Changes in mitochondrial redox state, membrane potential and calcium precede mitochondrial dysfunction in Doxorubicin -induced cell death. Biochim Biophys Acta, 2011; 1813(6):1144-52.

Lagha AB, Grenier D. Tea polyphenols inhibit the activation of NF- $\mathrm{KB}$ and the secretion of cytokines and matrix metalloproteinases by macrophages stimulated with Fusobacterium nucleatum. Sci Rep, 2015; 6(34520):1-11. 
Lecumberri E, Dupertuis YM, Miralbell R, Pichard C. Green tea polyphenol epigallocatechin-3-gallate (EGCG) as adjuvant in cancer therapy. Clin Nutr, 2013; 32(6):894-903.

Mandziuk S, Gieroba R, Korga A, Matysiak W, JodlowskaJedrych B, Burdan F, Poleszak E, Kowalczyk M, Grzycka-Kowalczyk L, Korobowicz E, Jozefczyk A. The differential effects of green tea on dosedependent doxorubicin toxicity. Food Nutr Res, 2015; 59:29754.

Mannervik B, Guthenberg C. Glutathione transferase (human placenta). In: Jakoby WB (ed.) Methods in enzymology. Academic Press, New York, NY, vol. 77, pp. 231-5, 1981.

Marklund S, Marklin G. Involvement of the superoxide anion radical in the autoxidation of pyrogallol and a convenient assay for superoxide dismutase. Eur J Biochem, 1974; 47:469-74.

Mohamed RH, Karam RA, Amer MG. Epicatechin attenuates Doxorubicin-induced brain toxicity: critical role of TNF- $\alpha$, iNOS and NFкB. Brain Res Bull, 2011; 86(1-2):22-8.

Mukhtar H, Ahmad N. Tea polyphenols: prevention of cancer and optimizing health. Am J Clin Nutr, 2000; 71(6 Suppl):1698S-702S.

Murray R. Alanine aminotransferase. In: Kaplan A, Pesce AJ (eds.). Methods in clinical chemistry. The C.V. Mosby Co, St Louis, Toronto, Princeton, pp. 1088-90, 1984a.

Murray R. Aspartate aminotransferase. In: Kaplan A, Pesce AJ (eds.). Methods in clinical chemistry. The C.V. Mosby Co, St Louis, Toronto, Princeton, pp. 1112-6, 1984b.

Nakagami T; DECODA Study Group. Hyperglycaemia and mortality from all causes and from cardiovascular disease in five populations of Asian origin. Diabetologia, 2004; 47:385-94.

Okamoto M, Leung KP, Ansai T, Sugimoto A, Maeda N. Inhibitory effects of green tea catechins on protein tyrosine phosphatase in Prevotella intermedia. Oral Microbiol Immunol, 2003; 18(3):192-5.

Panjrath GS, Patel V, Valdiviezo CI, Narula N, Narula J, Jain D. Potentiation of doxorubicin cardiotoxicity by iron loading in a rodent model. J Am Coll Cardiol, 2007; 49:2457-64.

Patel N, Joseph C, Corcoran GB, Ray SD. Silymarin modulates Doxorubicin-induced oxidative stress, $\mathrm{Bcl}-\mathrm{xL}$ and $\mathrm{p} 53$ expression while preventing apoptotic and necrotic cell death in the liver. Toxicol Appl Pharmacol, 2010; 245(2):143-52.

Patil M, Sheth KA, Adarsh CK. Elevated alpha fetoprotein, no hepatocellular carcinoma. J Clin Exp Hepatol, 2013; 3:162-4.

Pedrycz A, Czerny K. Immunohistochemical study of proteins linked to apoptosis in rat fetal kidney cells following prepregnancyadriamycin administration in the mother. Acta Histochem, 2008; 110:519-23.

Pradhan SC, Girish C. Hepatoprotective herbal drug, silymarin from experimental pharmacology to clinical medicine. Indian J Med Res, 2006; 124:491-504.

Preuss HG, Jarrel ST, Scheckenobac R, Lieberman S, Anderson RA. Comparative effects of chromium vanadium of Gymnema sylvester on sugar-induced blood pressure elevations in SHR. J Am Coll Nutr, 1998; 17(2):116-23

Quine SD, Raghu PS. Effects of (-)-epicatechin, a flavonoid on lipid peroxidation and antioxidants in streptozotocin-induced diabetic liver, kidney and heart. Pharmacol Rep, 2005; 57:610-5.

Rahman I. Comparative analysis of phytochemical constituents, antibacterial and antioxidant activity of green tea (Camellia sinensis). A Dissertation submitted to Brac University in partial fulfilment of the requirements for the Bachelor of Science in Biotechnology, Biotechnology Programme, Department of Mathematics and Natural Sciences BRAC University Dhaka, Bangladesh, pp. 1-74, 2016.

Rahmani AH, Al shabrimi FM, Allemailem KS, Aly SM, Khan MA. Implications of green tea and its constituents in the prevention of cancer via the modulation of cell signaling pathway. BioMed Res Int, 2015; Article ID 925640:1-2.
Rani R, Nagpal D, Gullaiya S, Madan S, Agrawal SS. Phytochemical, pharmacological and beneficial effects of green tea. Int $\mathrm{J}$ Pharmacogn Phytochem Res, 2014; 6(3):420-6.

Rizvi SI, Zaid MA. Intracellular reduced glutathione content in normal and type 2 diabetic erythrocytes: effect of insulin and (-)-epicatechin. J Physiol Pharmacol, 2001; 52:483-8.

Rizvi SI, Zaid MA, Anis R, Mishra N. Protective role of tea catechins against oxidation-induced damage of type 2 diabetic erythrocytes Clin Exp Pharmacol Physiol, 2005; 32:70-5.

Rozza AL, Hiruma-Lima CA, Tanimoto A, Pellizzon $\mathrm{CH}$. Morphologic and pharmacological investigations in the epicatechin gastroprotective effect. Evid Based Complement Alternat Med, 2012; Article ID 708156:1-8.

Saad SY, Najjar TA, Al-Rikabi AC. The preventive role of deferoxamine against acute Doxorubicin-induced cardiac, renal and hepatic toxicity in rats. Pharma Col Res, 2001; 43:211-8.

Sayed-Ahmed MM, Al-Shabanah OA, Hafez MM, Aleisa AM, Al-Rejaie SS. Inhibition of gene expression of heart fatty acid binding protein and organic cation/carnitine transporter in doxorubicin cardiomyopathic rat model. Eur J Pharmacol, 2010; 640:143-9.

Sendensky A, Dufour JF. Liver physiology. In: Ginès P, Kamath P, Arroyo V (eds.). Chronic liver failure (mechanisms and management), clinical gastroenterology. Humana Press, Springer Science \& Business Media, LLC, Springer Nature, Switzerland, pp. 33-45, 2011. Available via https//www.springer.com/gp/book/9781607618652. doi:10.1007/978-160761-866-9 2

Shankar S, Chen Q, Srivastava RK. Inhibition of PI3K/AKT and MEK/ERK pathways act synergistically to enhance antiangiogenic effects of EGCG through activation of FOXO transcription factor. J Mol Signal, 2008; 3(7):1-11.

Shankar S, Suthakar G, Srivastava RK. Epigallocatechin-3gallate inhibits cell cycle and induces apoptosis in pancreatic cancer. Front Biosci, 2007; 12:5039-51.

Shanmugam B, Shanmugam KR, Ravi S, Subbaiah GV, Ramakrishana C, Mallikarjuna K, Reddy KS. Exploratory studies of (-)-epicatechin, a bioactive compound of Phyllanthus niruri, on the antioxidant enzymes and oxidative stress markers in D-galactosamineinduced hepatitis in rats: a study with reference to clinical prospective. Pharmacogn Mag, 2017; 13:S56-62.

Shimizu M, Deguchi A, Lim JT, Moriwaki H, Kopelovich L, Weinstein IB. Epigallocatechin gallate and polyphenon E inhibit growth and activation of the epidermal growth factor receptor and human epiderma growth factor receptor-2 signaling pathways in human colon cancer cells. Clin Cancer Res, 2005; 11:2735-46.

Skrzydlewska E, Ostrowska J, Farbiszewski R, Michalak K. Protective effect of green tea against lipid peroxidation in the rat liver, blood and the brain. Phytomed, 2000; 9:232-8.

Spencer JP, Schroeter H, Kuhnle G, Srai SK, Tyrrell RM, Hahn U, Rice-Evans C. Epicatechin and its in vivo metabolite, 3'-O-methyl epicatechin, protect human fibroblasts from oxidative-stress-induced cell death involving caspase-3activation. Biochem J, 2001; 354(Pt 3):493-500.

Subhashini R, Mahadeva Rao US, Sumathi P, Gunalan G. A comparative phytochemical analysis of cocoa and green tea. Indian J Sci Technol, 2010; 3(2):188-92.

Swanston-Flatt SK, Day C, Flatt PR, Bailey CJ. Evaluation of antihyperglycemic properties of traditional plant treatment for diabetes in streptozotocin diabetic and $\mathrm{db} / \mathrm{db}$ mice. In: Shafrir E (ed.). Frontiers in diabetes research. Lesson for animal diabetes. Smith-Gordon, London, UK, vol. 3, pp. 286-93, 1990

Tacar O, Sriamornsak P, Dass CR. Doxorubicin: an update on anticancer molecular action, toxicity and novel drug delivery systems. J Pharm Pharmacol, 2013; 65(2):157-70. 
Tadesse A, Hymete A, Bekhit AA, Mohammed SF. Quantification of total polyphenols, catechin, caffeine, 1-theanine, determination of antioxidant activity and effect on antileishmanial drugs of Ethiopian tea leaves extracts. Phcog Res, 2015; 7:7-14.

Tangpong J, Cole MP, Sultana R, Joshi G, Estus S, Vore M, Clair WS, Ratanachaiyavong S, Clair DK, Butterfield DA. Butterfield, adriamycin-induced, TNF-alpha-mediated central nervous system toxicity. Neurobiol Dis, 2006; 23:127-39.

Therland KL, Stubbe J, Thiesson HC, Ottosen PD, Walter S, Sorensen GL, Skøtt O, Jensen BL. Cycloxygenase-2 is expressed in vasculature of normal and ischemic adult human kidney and is colocalized with vascular prostaglandin E2 EP4 receptors. J Am Soc Nephrol, 2004; 15:1189-98.

Tietz NW, Rinker AD, Shaw LM. International Federation of Clinical Chemistry. IFCC methods for the measurement of catalytic concentration of enzymes. Part 5. IFCC method for alkaline phosphatase (orthophosphoric-monoester phosphohydrolase, alkaline optimum, EC 3.1.3.1). IFCC Document Stage 2, Draft 1, 1983-03 with a view to an IFCC Recommendation. Clin Chim Acta, 1983; 135(3):339F-67F.

Trivedi PP, Kushwaha S, Tripathi DN, Jena GB. Cardioprotective effects of hesperetin against doxorubicin-induced oxidative stress and DNA damage in rat. Food Chem Toxicol, 2011; 11(3):215-25.

Vannier E, Miller LC, Dinarello CA. Coordinated antiinflammatory effects of interleukin 4: Interleukin 4 suppresses interleukin 1 production but up-regulates gene expression and synthesis of interleukin 1 receptor antagonist. Proc Nat Acad Sci USA, 1992; 89:407680 .

Vasconcelos PC, Seito LN, Di Stasi LC, Akiko Hiruma-Lima C, Pellizzon $\mathrm{CH}$. Epicatechin used in the treatment of intestinal inflammatory disease: an analysis by experimental models. Evid Based Complement Alternat Med, 2012; article ID 508902:1-12.

Wang G, Zhang J, Liu L, Sharma S, Dong Q. Quercetin potentiates Doxorubicin mediated antitumor effects against liver cancer throughp53/Bcl-xl. PLoS One, 2012; 7:51764.

Wen-Jun M, Hai-Yong W, Li-Song T. Correlation analysis of preoperative serum alpha-fetoprotein (AFP) level and prognosis of hepatocellular carcinoma (HCC) after hepatectomy. World J Surg Oncol, $2013 ; 11: 212-9$.
Xi L, Zhu S, Das A, Chen D, Durrant, Hobbs DC, Lesnefsky EJ, Kukreja RC. Dietary inorganic nitrate alleviates doxorubicin cardiotoxicity: mechanisms and implications. Nitric Oxide, 2012; 26(4):274-84.

Xin Y, Li-Li W, Wan J, Peng X, Cheng G. Alleviation of the acute doxorubicin-induced cardiotoxicity by Lycium barbarum polysaccharides through the suppression of oxidative stress. Food Chem Toxicol, 2011; 49(1):259-64

Yagmurca M, Bas O, Mollaoglu H, Sahin O, Nacar A, Karaman $\mathrm{O}$, Songur A. Protective effects of erdosteine on doxorubicin-induced hepatotoxicity in rats. Arch Med Res, 2007; 38(4):380-5.

Yang XL, Fan CH, Zhu HS. Photo-induced cytotoxicity of malonic acid [C60] fullerene derivatives and its mechanism. Toxicol In Vitro, 2002; 16:41-6.

Yanishlieva-Maslarowa NN, Heinonen IM. Sources of natural antioxidants: vegetables, fruits, herbs, spices and teas. In: Pokorny J, Yanishlieva N, Gordon M (eds.). Antioxidants in food- practical applications. CRC Press, Woodhead Publ., Cambridge, UK, pp. 210-49, 2001.

Yoshida T, Majors RE. High-speed analyses using rapid resolution liquid chromatography on $1.8-\mu$ porous particles. J Sep Sci, 2006; 29:2421-32.

Zhao X, Zhang J, Tong N, Chen Y, Luo Y. Protective effects of berberine on doxorubicin-induced hepatotoxicity in mice. Biol Pharm Bull, 2012; 35(5):796-800.

How to cite this article:

Ahmed OM, Abdul-Hamid MM, El-Bakry AM, Mohamed HM, Rahman FE-ZSA. Camellia sinensis and epicatechin abate doxorubicin-induced hepatotoxicity in male Wistar rats via their modulatory effects on oxidative stress, inflammation, and apoptosis. J Appl Pharm Sci, 2019; 9(04):030-044. 